\title{
Una entrevista con Antonio Gilman Guillén. Primera parte
}

\author{
An interview with Antonio Gilman Guillén. Part 1
}

\author{
Juan Manuel Vicent García ${ }^{a}$, M. Isabel Martínez Navarrete ${ }^{a}$ y Pedro Díaz-del-Río \\ Español $^{a}$
}

\section{RESUMEN}

Antonio Gilman Guillén, Profesor Emérito de la California State University-Northridge (EE. UU.) nació en Newton (Massachusetts, EE. UU.) en 1944 del hispanista Stephen Gilman y Teresa Guillén, hija del poeta Jorge Guillén. Se educó en Harvard College (Grado en Filología Clásica, 1965), Cambridge University (Grado y Master en Arqueología Prehistórica, 1967 y 1971 respectivamente) y Harvard University (Doctor en Antropología, 1974).

El profesor Gilman es un autor de referencia en los EE. UU. sobre la Prehistoria Reciente europea desde hace 40 años. Su dedicación particular a la península ibérica desde la década de 1970 ha influido en la investigación de este territorio en un doble sentido. Por una parte ha favorecido de manera significativa la internacionalización de los yacimientos peninsulares y de los arqueólogos que los estudian en la comunidad académica de lengua inglesa. Por otra, ha mostrado que hay alternativas a la arqueología históricocultural, predominante en las universidades europeas. Un buen ejemplo es su interpretación económico-política del registro arqueológico de la Prehistoria Reciente, cuya unidad de análisis es el surgimiento de la desigualdad social. La incorporación del Análisis de Captación de Recursos, entre otras estrategias de la investigación en Geografía, ha sido fundamental para mostrar la viabilidad del proyecto alternativo. Su influencia debe mucho también a su disponibilidad a incorporarse tanto a equipos liderados por arqueólogos locales, como a tareas de evaluación y asesoramiento en organismos públicos de investigación y revistas científicas, como Trabajos de Prehistoria. La Junta de Andalucía así lo reconoció concediéndole en 2012 la Medalla Menga.

La entrevista con Antonio Gilman aprovechó su estancia en la Residencia de Estudiantes (Madrid) durante noviembre de 2019 y se publicará en dos entregas. Este primer artículo se centra en los aspectos biográficos de su formación intelectual y muestra el entrecruzamiento del azar y, por tanto, de la decisión individual, con las redes familiares, de clase, culturales y académicas en una trayectoria científica de excelencia.

\begin{abstract}
Antonio Gilman Guillén, Professor Emeritus at California State University-Northridge (USA) was born in Newton (Massachusetts, USA) in 1944, son of the hispanist Stephen Gilman and Teresa Guillén, daughter of the poet Jorge Guillén. He was educated at Harvard College (A.B. Classics, 1965), Cambridge University (B.A. and M.A. in Prehistoric Archeology, 1967 and 1971 respectively) and Harvard University (Ph.D. Anthropology, 1974). Professor Gilman has been a US authority in the subject of the Late Prehistory of Europe for the last 40 years. His particular commitment to the Iberian Peninsula since the 1970s has had a double impact in research dynamics. It has significantly favored the internationalization of Iberian prehistoric sites and the native archaeologists who study them in the English-speaking academic community. In addition, Gilman has championed a materialist alternative to Culture-History approaches to Archaeology that have been the theoretical mainstream in European universities for decades. A good example is his political-economy approach to the European Late Prehistoric archaeological record, whose unit of analysis has been the emergence of social inequality. His use of site catchment analysis, among other Geographical research strategies, has been essential to show the feasibility of his alternative project. His intellectual influence also owes much to his readiness to participate in Spanish-led archaeological teams, as well as his assessment and commitment in advising public research organizations and scientific journals, such as Trabajos de Prehistoria. The Junta de Andalucia recognized his influential trajectory by awarding him the Menga Medal in 2012.

This interview with Antonio Gilman took advantage of his stay during November 2019 at the Residencia de Estudiantes (Madrid) and will be published in two parts. This first article focuses on the biographical aspects of his intellectual background, highlighting the intersection of chance - and therefore individual decision, family, class, cultural and academic networks in creating a scientific pathway of excellence.
\end{abstract}

a CSIC. Instituto de Historia. C/ Albasanz 26-28. 28037 Madrid. España. Correos e.: juan.vicent@cchs.csic.es http://orcid.org/0000-0003-28341985; isabel.martinez@cchs.csic.es https://orcid.org/0000-0002-3060-6033; pedro.diazdelrio@cchs.csic.es https://orcid.org/0000-0002-4150-6185 de uso y distribución "Creative Commons Reconocimiento 4.0 Internacional" (CC BY 4.0) 
Palabras clave: Gilman; Guillén; Historiografía; Fuente oral; Estados Unidos de América; Península ibérica; Prehistoria; Materialismo histórico; Funcionalismo.

Key words: Gilman; Guillén; Historiography; Oral source; United States of America; Iberian peninsula; Prehistory; Historical materialism; Functionalism.

\section{INTRODUCCIÓN: ¿POR QUÉ Y PARA QUÉ ESTA ENTREVISTA?}

La entrevista a una persona relevante por su trayectoria vital o profesional suele tener un estilo narrativo y, a veces, un punto laudatorio. También es una herramienta de investigación insustituible, si los temas escogidos están bien preparados y la persona que debe tratarlos, además de ser la adecuada, está comprometida con el proyecto. Es decir, interviene activamente en la conversación matizando sus respuestas, incorporando cuestiones no tenidas en cuenta o excluyendo otras irrelevantes. Resultan paradigmáticas las entrevistas a prehistoriadores bien conocidos en la península ibérica como André Leroi-Gourhan (Rocquet 1982) y Jean Guilaine (2011) o Lewis Binford (Renfrew 1987) y Colin Renfrew (Bradley 1993; Harding 2009), publicadas en formato libro o como contribuciones a Current Anthropology u otras revistas internacionales de referencia.

Las sucesivas "pérdidas de la inocencia" que se han producido desde la década de 1970 en la teoría y metodología arqueológicas pueden revalorizar el papel de la entrevista en cuanto combinación inevitable de datos biográficos y profesionales que devela la grande porosité de la frontière entre travail savant et vie personnelle (Bourguet, en Lacour y Lamy 2018: 223).

Esta entrevista reúne condiciones para ser una fuente histórica relevante y está en sus objetivos lograrlo. Antonio Gilman Guillén es un referente en los EE.UU, su país, para el conocimiento de la Prehistoria Reciente europea desde hace 40 años y desde la década de 1970 en la península ibérica donde viene trabajando de modo continuo (véase $\mathrm{AC} 1$ ). Su biografía es un testimonio directo del desarrollo de la investigación prehistórica en la península ibérica desde mediados de los 1960 a la actualidad y, a la vez, de la sociología e historia intelectual del mundo académico en Estados Unidos e Inglaterra en esos años. Las intervenciones del profesor Gilman combinan lo etic y lo emic. La mirada externa a España y a la investigación local procede de su formación en su país de origen y en Inglaterra y del contexto familiar paterno, clave de su reivindicada identidad de ciudadano de los EE.UU. El compromiso con la arqueología española deriva de su contexto familiar materno de hispanistas, emigrados por motivos académicos y políticos a los EE.UU. Ambas perspectivas convergen en un ambiente familiar trilingüe, liberal, y crítico donde la capacidad intelectual y la educación de excelencia representaban la normalidad.

Los entrevistadores conocieron al profesor Gilman con motivo del desarrollo de sus sucesivas tesis doctorales $(1985,1989,1999)$, primero a través de la lectura de sus publicaciones y, después, manteniendo un contacto directo con él durante sus estancias en Madrid. Una vez incorporados al Consejo Superior de Investigaciones Científicas (CSIC) los tres han compartido proyectos con Antonio Gilman. Probablemente el más persistente haya sido su vinculación al equipo editorial de la revista Trabajos de Prehistoria culminada con su nombramiento como director de la misma durante el cuatrienio 2015-2018, convirtiéndose en el primer director extranjero de una revista española de humanidades de la Editorial CSIC (Rodríguez Yunta et al. 2019).

\section{CÓMO SE HIZO}

Esta entrevista, cuyo género contaba con antecedentes en la revista (Ruiz-Zapatero y Vicent 1992; Risch 2013), fue una de las iniciativas de los miembros del Consejo de Redacción de Trabajos de Prehistoria para homenajear a su director saliente. Para ello se aprovechó la oportuna estancia del profesor Gilman en la Residencia del Estudiantes durante el último trimestre de 2019. La Residencia es su alojamiento habitual en Madrid y está cargada de referencias personales conectadas con su abuelo, Jorge Guillén.

La entrevista se celebró en tres sesiones, los días 19, 22 y 28 de noviembre (Thanksgiving Day) a partir de una estructura propuesta por Juan Manuel Vicent, consensuada con los firmantes y aceptada por Antonio Gilman y el consejo de redacción. Maribel Martínez transcribió el archivo sonoro generado. Esta primera versión fue revisada por los participantes manteniendo la oralidad. Ambos originales, grabación y transcripción, se incorporaron al Archivo del Centro de Ciencias Humanas y Sociales perteneciente a la Biblioteca Tomás Navarro Tomás del CSIC. La redacción de la variante que aquí se ofrece, ya sin reiteraciones ni latiguillos y completando las interrupciones involuntarias, simplifica el texto y garantiza la correcta comprensión de los diálogos. En este momento se valoró la extensión de los temas tratados para su distribución en diferentes artículos que se publicarán en este número y el siguiente de la revista.

Los temas que constituyen esta primera parte tienen un hilo conductor cronológico. Se inician con el en-

Trab. Prehist., 77, N. ${ }^{\circ}$ 1, enero-junio 2020, pp. 7-29, ISSN: 0082-5638

https://doi.org/10.3989/tp.2020.12244 
torno familiar de Antonio Gilman y sus primeros estudios escolares; siguen con su formación en las Universidades de Harvard y Cambridge, su doctorado en Harvard, su primer trabajo en la Universidad de Wisconsin, en Oshkosh y su llegada a la Universidad del Estado de California en Northridge, marco institucional de su investigación en España, y donde se jubiló. El documento finaliza con su primer contacto con la Prehistoria reciente del Sureste de la península ibérica, la gestación y aplicación del programa de site catchment analysis y el subsiguiente proyecto sobre la Edad del Bronce en La Mancha oriental, todo ello asociando los programas metodológicos con los contextos académicos e institucionales en los que se desarrollaron.

El estudio crítico subsecuente incluyó citas bibliográficas en texto y notas aclaratorias al pie para contextualizar las respuestas de Antonio Gilman. Él mismo las modificó, completó o suprimió en su caso. Salvo que se diga lo contrario, las notas son responsabilidad de los entrevistadores.

\section{LA ENTREVISTA}

\subsection{Entorno familiar y formación}

Pedro Díaz-del-Río (PDR): En primer lugar nos gustaría que nos contases algunos datos biográficos para entender el contexto familiar en el que naciste y te criaste.

Antonio Gilman (AG): Nací en abril de 1944, en Newton, Massachussets, hijo del norteamericano Stephen Gilman (1917-1986) (Millán 1986) y la española Teresa Guillén (1922-2019), emigrada de España con su padre, Jorge Guillén (1893-1984), su madre Germaine Cahen (1897-1947) y su hermano Claudio (1924-2007). Ella salió de España en 1936 y mis abuelos en julio de 1938. El interés de mi padre por España arranca de una larga estancia con sus padres en Torremolinos en 1934. Como estudiante en Princeton University, mi padre fue alumno primero de Augusto Centeno y luego de Américo Castro ${ }^{1}$. De hecho fue el alumno preferido de Don Américo. Mi madre hizo sus estudios universitarios en Wellesley College, en donde su padre había conseguido un puesto permanente. Ambos se encontraron durante la Escuela de Verano de Lenguas del Middlebury College. Creo que mi padre

\footnotetext{
${ }^{1}$ La relación entre Jorge Guillén y Américo Castro "se remonta a los años diez del siglo XX, cuando el entonces joven poeta entra en contacto con el Centro de Estudios Históricos, que dirigía en Madrid don Ramón Menéndez Pidal, y cuya sección de Lexicografía estaba a cargo de Américo Castro, ocho años mayor que Guillén” (Triana Cardona 2018).
}

estaba ahí más para aprender francés que castellano, el cual ya dominaba. Se casaron en 1943 .

PDR: ¿Tu madre asistía como estudiante a esa Escuela de Verano?

AG: No creo que ella estuviese ahí de estudiante, más bien como miembro de la familia de mi abuelo, porque él daba clases en Middlebury. Además, mi madre era completamente bilingüe en francés y castellano pues su madre era francesa. Mi padre tuvo una carrera que le llevó a varios sitios: Princeton como doctorando y después assistant professor después de la guerra, luego en 1948 pasó a la Ohio State University $(O S U)$ y a partir del otoño de 1955 a Harvard. Una vez instalados en Massachusetts fui a una escuela privada que estaba cerca de casa, la Belmont Hill School (1956-1961) y luego estudié Latín y Griego como undergraduate en Harvard (1961-1965).

PDR: ¿Seguías viviendo en casa de tus padres?

AG: No, ya no. Yo vivía en los alojamientos para estudiantes, pero volvía a casa los domingos para comer.

PDR: ¿Cuándo fue tu primer contacto con la escuela? ¿En Ohio?

AG: Sí, a los 6 años, no habiendo estado en ningún colegio antes (Fig. 1). Empecé en enero de 1951, porque mi padre había tenido una beca todo el año de la Solomon R. Guggenheim Foundation y durante 1950 estuvimos en Europa. ¡Llegué a la escuela sin saber inglés! Lo entendía, pero como en casa la regla era que teníamos que hablar en español siempre... Fue una regla impuesta por mi padre, que creía que el bilingüismo era importante. Yo he estado traduciendo toda mi vida. Es una de las cosas que, como sabéis, hago con facilidad.

PDR: ¿Hiciste todos tus estudios de Primaria en Ohio?

AG: No. Durante los primeros tres años de Primaria iba a la escuela si estaba en Ohio, pero gran parte del tiempo no estaba.

PDR: ¿Por qué?

AG: Porque mi padre tenía un arreglo con la OSU por el que le pagaban un sabático trimestral de cada seis. Era parte de lo que le habían ofrecido para atraerle desde Princeton, una gran Universidad, a otra menos prestigiosa. Mi padre entonces decidió que podía tomarse un cuatrimestre ${ }^{2}$ sin salario y dar clases medio año. El resto del tiempo y para ahorrar nos íbamos en coche desde Columbus (Ohio) a Ciudad de México, donde mi padre podía estudiar. En el curso 1954-1955, por ejemplo, mi padre tuvo una beca de la Ford Foundation. Ese otoño sustituyó al hispanista Ernst Robert

\footnotetext{
2 OSU funcionaba con el quarter system: el año académico se divide en 4 trimestres.
} 


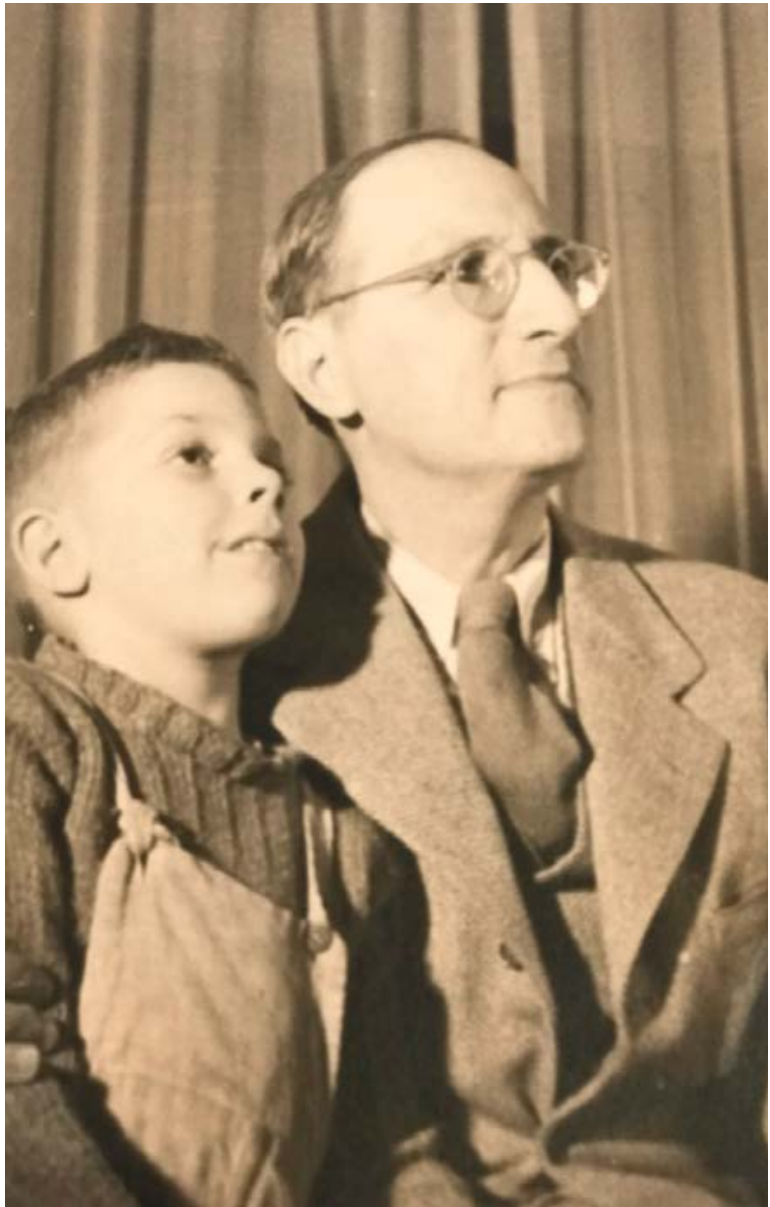

Fig. 1. Antonio Gilman Guillén a los 6 años con su abuelo Jorge Guillén. Fotografía realizada en Columbus (Ohio) o Wellesley (Massachusetts) (autoría desconocida, álbum familiar).

Curtius (Rubio Tovar 1997) en la Universidad de Bonn y como veterano de la Segunda Guerra Mundial pudo meternos a mí y mi hermana Isabel en la escuela de la base americana en Plittersdorf. Pero durante la primavera de 1955 pasó a Zurich y mi madre, Isabel y yo estuvimos en Valladolid y no fuimos a la escuela. Es decir, que yo iba a la escuela cuando podía. Si no recuerdo mal, en los primeros 6 años de escuela habré estado en la clase poco más de la mitad del tiempo.

PDR: O sea, que ibas a hacer los exámenes.

AG: Ni siquiera hacía eso, porque no hay exámenes en las escuelas primarias. Allí lo que se aprende son las 3 Rs (reading, 'riting \& 'rithmetic) y si eres un chico un poco listo, y yo lo era, entonces todo lo que se aprendía en la escuela infantil se podía resolver en poco tiempo. Es cierto que hay algunos huecos en esa educación. Por ejemplo, nunca aprendí a escribir en cursiva, porque el año en el que lo enseñaban no estuve en la escuela. Una vez asentados en Massachusetts estudié a tiempo completo. La Belmont Hill era una escuela privada con clases pequeñas que, como todas estas escuelas, favorecen a los niños con ciertas capacidades y garantizan que aquellos con menos también se eduquen. Era una buena escuela.

PDR: Ahí sí que tenías que examinarte, ¿no?

AG: Sí, bueno había exámenes al final de cada asignatura. Para entonces había exámenes, notas...

PDR: Cuéntanos un poco cuál era la percepción como niño de la vida cultural que se desenvolvía a tu alrededor, un entorno familiar de vínculos culturales y conexiones intelectuales extraordinarias.

AG: Yo era un niño inteligente y, por lo que parece, bastante rico $^{3}$. Me llevaba bien con los mayores, les preguntaba cosas: era un niño que participaba en la vida familiar de una manera activa y mantenía todo tipo de interacciones. Cuando mi abuelo Guillén enviudó en el año 1947, aprovechó cualquier momento en el cual no estaba dando clases en Wellesley para estar con nosotros. Venía de visita a Columbus, nosotros íbamos a Wellesley o coincidíamos en México. Wellesley tenía pisos para sus profesores y mi abuelo vivió en uno de ellos hasta su jubilación en el año 1958, cuando pasa a vivir con mis padres en la casa que teníamos en Arlington (Massachusetts). Al morir mi abuelo paterno, Stephen Gilman, la herencia permitió que en 1960 mis padres compraran una casa más grande de tres plantas en Cambridge, cerca de la universidad. El ático se convirtió en la residencia de mi abuelo e Irene Mochi-Sismondi, italiana, hija de un diplomático, con la que se había casado en segundas nupcias (Hernández 2004).

PDR: Por entonces tú ya estabas en la Facultad...

AG: Nos mudamos a Cambridge el verano antes de mi último año de high school. Mi abuelo se jubiló en 1958, pero ya me había tratado mucho durante mi infancia. Recuerdo que me tanteaba... "a ver lo que puede entender este niño"... Contrastaba la teoría de Tolstoi: la gran literatura es para todos. Cuando yo tenía 5 años me leía la adaptación modernizada del poema del Mío Cid de su amigo Don Pedro Salinas (1926), "a ver si el niño no lo entiende"... Bueno, pues el niño lo entendía, se acordaba, y como buen oyente de poesía épica quería que la recitación se repitiera.

Tras su jubilación mi abuelo decidió pasar el año en Europa. Empezó su viaje en verano y me llevó a Grecia durante un mes. Allí visitamos muchos lugares. Me encantó visitar los yacimientos arqueológicos.

\footnotetext{
3 En el sentido de la acepción 7 del término de la RAE: "adj. coloq. Dicho especialmente de un niño: Bonito y a la vez gracioso, encantador."
} 

logía.

PDR: Es quizás tu primer contacto con la Arqueo-

AG: Sí, absolutamente. Me acuerdo muy bien de ese viaje y las distintas visitas a los sitios. Era lo suficientemente mayor para que eso formase ya parte de mi memoria. Volví a Phaistos 59 años después y me acordaba bien del lugar.

PDR: Imagino que también forma parte de tu memoria la activa vida cultural que rodeaba el día a día de tu familia; la presencia de tu padre y abuelo, su relación con el mundo literario, el papel clave de tu madre a la hora de organizar reuniones en vuestra casa por las que pasaban renombrados académicos...

AG: Bueno, la fase del salón hispánico de mi madre empieza más bien después de mudarnos a Cambridge en 1960 (Rose 1988). Pero antes mis padres estaban en contacto frecuente con varias figuras tanto del exilio (Américo Castro, Francisco García Lorca, Max Aub, etc.) como de personas que habían hecho sus carreras en las Américas antes de la guerra (Joaquín Casalduero, Amado Alonso, etc.). Me acuerdo muy bien de ellos. Una vez instalados todos en la casa de Cambridge, mi abuelo atraía muchas visitas.

Pasaban por casa arquitectos (p. ej., José Luis Sert), artistas (p. ej., Eduardo Chillida) y muchas figuras literarias (Jorge Luis Borges, Octavio Paz...). Mi madre organizó una especie de salón al que invitaba a aquellos intelectuales y artistas del mundo hispánico que pasaban por Harvard (Christian 2020: 3). Mi abuelo vivió en Cambridge hasta que volvió definitivamente a España en el año 1976. Nunca tuvo un expediente político, mantuvo la ciudadanía española en el exilio y pudo volver sin problemas. Su primera visita después de la guerra sería en 1947 y se compró un piso en Málaga a finales de la década de los 60 , pero no estableció su residencia permanente en España hasta después de la muerte de Franco.

PDR: Cuéntanos cuál es el peso de las raíces españolas de tu familia en tu formación preuniversitaria. ¿Se consideraba una familia española?

AG: No, era una familia americana que hablaba el castellano en casa. Mi padre era completamente norteamericano. Sus antepasados emigraron de Inglaterra a finales del siglo XVII o principios del XVIII. La familia está en Wisconsin hasta principios del siglo XIX. El primer Gilman del cual tengo noticias detalladas es mi bisabuelo Stephen Warren Gilman (18571931), fundador del Department of Business Economics en la University of Wisconsin (Wright 1928). Mi abuelo paterno, Stephen Gilman (1887-1959), era Certified Public Accountant (CPA). En torno al año 1922 o 1923 decidió establecer su propia empresa, la International Accountants Society, donde daría cursos de preparación por correspondencia para habilitarse como CPA. En aquel entonces no existían la multitud de business schools que hay hoy en día en las universidades americanas. Las business schools estaban en su infancia, eran pocas y no satisfacían la demanda. Él estableció un sistema por el cual escribía una serie de ejercicios que la gente tenía que completar y sus contratados corregían. Era una especie de curso a distancia por correspondencia. Una vez que habías completado con éxito los ejercicios, podías presentarse al examen. Los estudiantes tenían éxito y en consecuencia la empresa prosperó. De hecho, prosperó tanto que su trabajo pudo consistir en poner al día los ejercicios, lo que le permitió, en efecto, jubilarse. Pero es que, además, pudo jubilarse prósperamente, pues en el verano de 1929 se dio cuenta que el crash iba a suceder y retiró todos sus valores de la bolsa inmediatamente antes de la crisis. Así que, como joven y próspero empresario jubilado, se dedicó a ser pintor, y tenemos varias de sus obras en casa, bastante buenas.

En 1934 decidió pasarse un año pintando en Torremolinos. Sacó a mi padre de la escuela y se lo llevó a España con su mujer (mi abuela) Martha y uncle Harry Rogers, el hermano menor de ella. Su cuñado era profesor de español en la OSU e iba como traductor y amigo. Había perdido a su mujer durante un parto y estaba lógicamente deprimido.

PDR: ¿Tu padre hablaba ya español?

AG: Fue entonces cuando lo aprendió. Supongo que habría recibido alguna clase de español porque era una de las lenguas optativas en la high school. Se podía escoger entre el español, el francés y el alemán, pero lo más normal era optar por el español. A fin de cuentas Estados Unidos y México son países vecinos. Pero es una vez en Princeton, durante su major, donde recibe clases de literatura española con Augusto Centeno (Garrido 2015) y orienta su carrera en esa dirección. Mi padre era un hombre de grandes capacidades, era el mejor alumno siempre... además de ser un hombre muy bueno.

En definitiva, yo era un niño criado en los Estados Unidos y me identifico como un norteamericano.

PDR: ¿Sentiste en algún momento una dualidad cultural en tu formación?

AG: Yo siempre era una persona completamente diferente de cualquier otra con la que me encontraba en la escuela o fuera de ella. No sólo venía de otro tipo de familia, era además un niño empollón, iba un año adelantado en la escuela, con gafitas, miope desde muy pequeño, irritante... era...

PDR: una persona distinta.

AG: Exacto, una persona distinta.

PDR: Eres el más mayor ¿de cuántos?

AG: Sí, de dos hermanas, Isabel, nacida en 1948 y Anita, nacida en 1957. Todos bajo la misma disciplina.

PDR: Todos hablando español. 
AG: Sí. De hecho, recién casado con Benedicte ${ }^{4}$ empecé el programa doctoral en Harvard. Naturalmente íbamos a comer en casa de mis padres los domingos y a Benedicte le sorprendió bastante la disciplina a la cual mi hermana pequeña todavía estaba sometida: ¡Dilo en español! Benedicte ya sabía bastante castellano y pudo incorporarse a esa dinámica familiar rápidamente.

PDR: Si no recuerdo mal, tu primera vinculación directa con la Arqueología surge en México, donde además conoces a Benedicte, cuando coincidís en la estación de Chiapas como alumnos del ColumbiaCornell-Harvard-Illinois Summer Field Studies Program in Latin America (CCHISFSPLA). iSe puede considerar esta estancia como un momento clave en tu evolución hacia la Arqueología y no hacia las Lenguas Clásicas?

AG: Vayamos por partes. Yo era estudiante de Clásicas porque era una cosa que se me daba bien. Las clases se impartían de una forma supongo que constante desde el siglo XVI. Por poner un ejemplo, en una asignatura sobre Sófocles debías leer tres obras a lo largo del cuatrimestre. La traducción es una especie de rompecabezas y resolverlo es un trabajo placentero (y además la literatura es excelente): tienes las reglas (la gramática), el vocabulario, el texto y a ver lo que puedes hacer. El profesor dice "las primeras seis líneas de hoy...", tú las traduces, él te corrige (no había "ella" por entonces en el Departamento) y después hace un comentario si es que hay algo que le parece interesante. El examen consiste en hacer una traducción y un comentario de una sección de esas mismas obras, ahora sí, sin diccionario. Una de las cosas que siempre he tenido es buena memoria (todavía es buena y de joven era mejor). Habiendo hecho la traducción y prestado atención en clase, los exámenes eran la cosa más fácil del mundo. Y encima era un major prestigioso, por decirlo así.

PDR: ¿En qué año fue eso?

AG: Estuve de undergraduate entre 1961 y 1965. En el verano de 1962 pude participar en las excavaciones en Ampurias gracias a la amistad de mis padres con Rafael Lapesa ${ }^{5}$, vecino en la residencia de catedráticos (calle Isaac Peral) de Martin Almagro, director de la Escuela de Verano en Ampurias. Participé, no como alumno, sino como peón en el campo de

\footnotetext{
${ }^{4}$ Benedicte [Fløystrup Gram] Gilman (1945 - 2019). Los Angeles Times from Jan. 26 to Feb. 10, 2019 https://www.legacy.com/obituaries/ latimes/obituary.aspx?n=benedicte-gilman\&pid=191365604

5 Rafael Lapesa Melgar también era amigo de su abuelo y había sido alumno de Américo Castro y, como catedrático de Historia de la lengua española, vivía en la "profesorera" de la Universidad Complutense de Madrid.
}

trabajo del Frente de Juventudes ${ }^{6}$. Don Martin excavaba con la mano de obra disponible: presos republicanos $\mathrm{y}$, cuando esos son liberados, batallones del ejército... Los del campo de trabajo podían pasar las tardes en la playa, pero a mí me permitieron asistir como alumno a las clases. $Y$ es entonces cuando me di cuenta de que aprender a clasificar terra sigillata era ¡aún más fácil que traducir del latín! Lo veías, lo reconocías y listo. Pasé en Ampurias dos veranos.

En 1963 vi un anuncio en el periódico estudiantil de Harvard, el Harvard Crimson, en el que se buscaba a alguien que supiese clasificar cerámica y leyese castellano para trabajar con el profesor Gordon Willey, un distinguido mesoamericanista (Sabloff 2004).

PDR: ¡Ni hecho a medida!

AG: Exactamente. Trabajé como assistant en el laboratorio del profesor Willey haciendo estas cosas dos o tres tardes a la semana durante los siguientes años, hasta 1965.

PDR: ¿Mientras hacías Clásicas?

AG: Sí.

PDR: Uno podría esperar que habiendo sido criado en un ambiente tan literario hubieses seguido esa carrera, como por otra parte hicieron tus propias hermanas.

AG: Bueno, solo mi hermana pequeña sigue en el family business.

PDR: Entonces, el momento de inflexión sucede en Ampurias.

AG: Todavía no tenía ideas fijas sobre qué carrera perseguir como graduado. El trabajo de traducir me resultaba placentero, pero me daba cuenta de que si seguía en Clásicas las opciones eran limitadas. Uno podía dedicarse a autores muy trabajados (Virgilio, Horacio, etc.) o a otros mucho menos interesantes (p. ej. preparar una nueva edición de Silio Itálico). Uno podría dedicarse a poesía religiosa bizantina o al latín medieval, pero habiéndome dado cuenta de lo que sería una carrera en Clásicas me pareció que no me gustaría a la larga.

Otra posibilidad era dedicarse a la Arqueología. Era una posibilidad factible, pero la Arqueología que yo había visto en Ampurias no me resultaba muy interesante. Don Martin era un gran gestor (soy un gran admirador de Don Martin Almagro, como he constatado por escrito, p. ej. Gilman 2018), pero su arqueología era perfectamente tradicional. Ampurias se excavaba como una minería de objetos de arte, por decirlo así, y, además, objetos de arte que, aparte de algún Esculapio que otro, eran bastante poco interesantes en sí.

${ }^{6}$ En 1961 el Frente de Juventudes pasa a denominarse Delegación Nacional de Juventudes. 
En el verano del 63 (mi segundo en Ampurias) Don Américo, que estaba pasando el verano en Playa de Aro, a una parada de autobús al sur de donde yo acampaba, me invitó a pasar un fin de semana con él y pude evitar la tienda de campaña una noche.

Hablando con Don Américo me comentó que había visitado el Museo de Ampurias y "claro, hay estas cosas - dice- muy particulares, los detalles de la Arqueología. Y, de hecho, uno tiene que empezar por ahí. Yo empecé -sigue Don Américo (me acuerdo bien de esta entrevista, recuerdo su contrariedad) - yendo pueblo a pueblo, buscando y documentando las isoglosas entre el castellano y el leonés pero, al fin y al cabo, uno tiene que dedicarse a cuestiones importantes".

Me pareció un buen consejo, pero a mí no se me ocurría exactamente qué cosas importantes se podían hacer dentro de esa Arqueología clásica que yo había visto. Lo mismo se podía decir del proyecto que me dió Willey el otoño siguiente: clasificar, siguiendo el libro de Caso y Bernal (1952), la colección de urnas funerarias zapotecas de Monte Albán que estaban en Harvard, en el Peabody Museum of Archaeology and Ethnology. Así que no sabía lo que iba a hacer exactamente...

PDR: Entonces, ¿en qué año de universidad supiste lo que querías hacer?

AG: En mi Senior year, en otoño de 1964. Ese verano había pedido plaza en el CCHISFSPLA7 por recomendación de mi padre, que había tenido un alumno, Renato Rosaldo, que a raíz de su participación se había pasado a la Antropología (Díaz Cruz 2006). El programa era para undergraduates y había cuatro puestos de destino: con Marvin Harris de Columbia en Salvador de Bahía (Brasil), con Allan Holmberg de Cornell en Perú, con Joseph Casagrande de Illinois en el Ecuador o con Evon Vogt de Harvard a San Cristóbal de las Casas en Chiapas. Solicité plaza y, como buen castellanoparlante, me asignaron directamente a Chiapas (Fig. 2). El Chiapas Project reflejaba la visión de Vogt $(1994)^{8}$, es decir, que los indígenas de los Altos de Chiapas, como hablantes de una lengua maya, eran representantes en el presente de la cultura maya. La cuestión era, por lo tanto, hacer una descripción de sus normas. Para aplicar el normativismo a la Etnografía, lo primero era tener una buena gramática de la lengua tzotzil y luego hacer descripciones de las partes particulares de su cultura para saber cómo pensaban. Se trataba de documentar las normas culturales que

\footnotetext{
${ }^{7}$ Columbia Daily Spectator VI (2) 24 November 1964: 3. Advertisements, columna 1. http://spectatorarchive.library.columbia.edu/cgi$\mathrm{bin} /$ columbia? $\mathrm{a}=\mathrm{d} \& \mathrm{~d}=\mathrm{cs} 19641124-02.2 .7 .1 \& \mathrm{e}=$ =-------en-20--20232--txttxIN-columbia-----

8 Véase también https://news.harvard.edu/gazette/story/2014/11 first-model-for-harvard-in-mexico/ (consulta 08-04-2020).
}

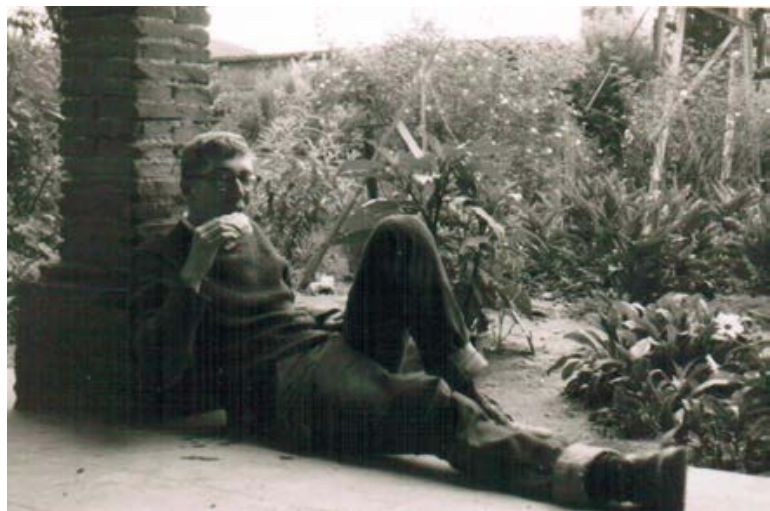

Fig. 2. Antonio Gilman Guillén en la Casa de Baños de San Cristóbal de las Casas (México), alojamiento del equipo del Chiapas Project, 1964 (autoría desconocida, álbum familiar).

caracterizarían lo que es ser maya desde el pasado hasta el presente.

Bueno, yo no sabía nada de eso, pero me parecía un tanto raro. Sabía algo de México, había hecho una especie de tesina en la high school sobre la presidencia de Lázaro Cárdenas y había tomado una asignatura en Harvard sobre la sociología de México con David McClelland (1961), el del famoso $N-A c h^{9}$. En el seminario preparatorio que recibimos antes del verano se enseñaba a hacer entrevistas de una manera sistemática siguiendo el programa de moda de la antropología cultural de aquel entonces, la Etnociencia. Era necesario recopilar los datos de una manera que fuese consistente entre un investigador y otro. Es decir, evitar interpretaciones discrepantes de un mismo fenómeno, como las existentes entre Oscar Lewis (1959) y Robert Redfield (1930) al tratar el caso de Tepoztlán. Para ello era necesario reproducir los mismos resultados mediante métodos de entrevistas sistemáticos, asumiendo que las personas guardan ideas en sus cabezas $\mathrm{y}$ estas son documentables sistemáticamente.

A cada uno de los participantes se le daba un proyecto, salvo el mío que estaba al margen de este programa. Yo debería leer y transcribir los documentos originales (guardados como un tesoro) del establecimiento de la "república de indios" de San Lorenzo Zinacantán. Vogt había hablado con el alcalde para que un alumno suyo pudiera acceder a ellos, pero ese verano no viajó a México. Dejó el programa en manos de un estudiante graduado suyo, George Collier, pero este no tenía la talla para que el alcalde cumpliera. Collier sugirió otros proyectos pero yo decidí desarrollar uno propio en el que entrevistaría a indios y ladi-

\footnotetext{
${ }^{9}$ N-Ach: Need for achievement o necesidad del logro, uno de los aspectos de la "Teoría de las tres necesidades".
} 
nos ancianos sobre sus memorias de la revolución mexicana (1910-1917) de la que ya se habían cumplido cincuenta años. Hice un buen número de entrevistas, pero tampoco tenía mucho que hacer.

Había en San Cristóbal de las Casas una institución, $\mathrm{Na}$ Bolom, establecida por el danés Frans Blom ${ }^{10}$, antiguo director del programa de estudios mesoamericanos en la Tulane University, recién fallecido en 1964. Por entonces, su viuda, Trudy Blom (Nuñez-Johnsson 2015), mantenía la institución, que contaba con una residencia, una biblioteca y un refectorio que daba cosas francamente buenas. Cuando tenía una tarde libre iba a comer y pasaba la tarde en la biblioteca. En el curso de leer lo que había por ahí, saqué Sons of the Shaking Earth (Wolf 1959), un libro entonces bastante reciente. Lo leí de una sentada y fue una revelación: ¡ahora entendía lo que sucedía y cuál era la dificultad del programa de Vogt! No nos había enseñado ese libro porque el texto de Eric Wolf demostraba a las claras que la cultura maya del presente era el producto de 450 años de historia, es decir, que la "esencia maya" simplemente no existía. Lo leí y para mí fue todo un mazazo.

Volví a Harvard y ese otoño decidí que quizás debería apuntarme a una asignatura de Arqueología, es decir, estudiarla en serio y no sólo hacer prácticas, estar ahí clasificando cerámica o poniendo siglas en los galbos... Nunca había asistido a una clase de Arqueología, pero pedí la entrada en el curso, ya avanzado, de Prehistoria del Viejo Mundo, Cultural Prehistory of the Old World, impartida por el profesor Hallam Movius, un distinguido paleolitista (Bricker 2007).

PDR: ¿Por qué Movius? Vista tu licenciatura en Clásicas, tu experiencia en Grecia, Ampurias... ¿por qué no una clase en Arqueología clásica?

AG: ¡Porque no había tal clase! En Harvard (como en las universidades americanas en general) la introducción a la Arqueología se hacía en Prehistoria y, después, uno podía estudiar otras cosas, pero no había un programa de Arqueología clásica como tal puesto que era parte de la Historia del Arte. Otra compañera de Chiapas, Victoria Reifler ${ }^{11}$, que ha llegado a ser una muy distinguida antropóloga, me recomendó a quien por entonces era su marido, Harvey Bricker (2007), el ayudante de curso de Movius. Así que, sin haber pasado por la clase de introducción, Vicky habló con Harvey y me aceptaron.

PDR: O sea que, realmente, el curso de Movius es el primer contacto directo con la Prehistoria. Creo recordar oírte decir que el curso de Prehistoria de Movius era fundamentalmente un curso sobre el Paleolítico.

\footnotetext{
${ }^{10} \mathrm{https} / /$ www.nabolom.org/ (consulta 29-01-2020).

11 Victoria Reifler Bricker https://drclas.harvard.edu/news/chiapasproject (consulta 09-04-2020).
}

AG: Sí, era un paleolitista. Excavaba en Les Eyzies (Movius 1975). De hecho es una figura importante para el Paleolítico europeo.

PDR: Cuéntanos algo de esta asignatura y de tu relación con el profesor Movius.

AG: Bueno, yo era uno de cuarenta alumnos en esa clase y realmente no tuve ninguna relación directa con él durante esa asignatura.

La dinámica era la siguiente: Movius daba dos clases por semana y uno se reunía con el ayudante de curso, Harvey, otro día a la semana para resolver dudas. Mi contacto con el profesor consistía en asistir a sus clases. Recuerdo una de ellas, en la que defendía el análisis de atributos como el método moderno que debería reemplazar a esta especie de tipología-lista desordenada del sistema Bordes de descripción. El y Bordes eran amigos y rivales, por así decirlo. Al fin y al cabo, trabajaba en Les Eyzies porque Bordes abogaba por él, pero el suyo era otro punto de vista científico. En un momento de esa clase dice: "algunas veces desearía tener un botón en esta mesa que, al apretarlo, cambiara todas las tipologías de una vez por todas". Los alumnos nos imaginamos a todos los profesores en los laboratorios de Burdeos, Paris y demás cayéndose muertos en el acto. Uno aprendía cosas interesantes en esa clase.

PDR: Una especie de avanzadilla de la crítica que luego hace Binford a Bordes.

AG: Binford empezó por ahí pero pasó a enfoques funcionalistas. El análisis de atributos es una forma de hacer el normativismo de manera más científica y más precisa. Es parte de esta ola de la Etnociencia, un programa distinto del que eventualmente propone Binford, que es funcionalista y etnoarqueológico.

Durante el curso de Movius uno podía hacer un examen parcial a mitad de curso, pero yo nunca estaba lo suficientemente preparado a mediados del curso; tenía la tendencia de reservarme para el final. Entonces opté por escribir una especie de ensayo de 40 o 50 páginas sobre la Revolución Neolítica. Movius prefería que lo hiciésemos así, de tal forma que él no tuviera que dedicar tiempo en clase a hablar de eso. Entre toda una bibliografía preparada que estaba en la biblioteca reservada para todos los que hacían estos estudios estaban varios textos de Childe. Uno de ellos era Man makes himself. Cuando lo leí vi inmediatamente la conexión con el punto de vista de Eric Wolf, es decir, me di cuenta que uno podía hacer cosas interesantes en Arqueología, cosas que no fueran ejercicios tipológicos y trabajos por el estilo, uno podía...

PDR: Hacer lo que te dijo Américo Castro que debías hacer.

AG: Exactamente. Entonces me dieron una beca de estudios de un año (que mis padres pudieron extender a otro más) para estudiar en Cambridge (Reino

Trab. Prehist., 77, N. ${ }^{\circ}$ 1, enero-junio 2020, pp. 7-29, ISSN: 0082-5638

https://doi.org/10.3989/tp.2020.12244 
Unido) donde uno podía dedicarse a la Arqueología europea en serio. Comprendía que, si iba a hacer Prehistoria, debería hacerlo preferentemente en un país en el que tuviese conexiones y, por otro lado, me gustase estar.

Por aquel entonces el conservador de arqueología europea en el Peabody Museum era Hugh O'Neill Hencken (Treaster 1981). Hencken era, como decimos en los EE.UU., a-dollar-a-year-man: le daban un salario nominativo porque era una persona que vivía de sus propios medios económicos. Durante muchos años se había dedicado a distintos periodos de la prehistoria de Europa y el Mediterráneo: un programa en Irlanda entre 1932 y 1936 (Carew 2018), otro en el norte de África después de la Segunda Guerra Mundial, etc. Cuando yo le conocí había pasado a trabajar sobre Hallstatt y Etruscos, los principios de la Edad del Hierro en Centroeuropa y en Italia, pero quería que alguien acabase de estudiar y publicase sus excavaciones del norte de África. La parte paleolítica la había publicado Bruce Howe (1967) y Hencken buscaba alguien que se hiciese cargo del registro postpaleolítico. Yo le había sido recomendado para esta misión por Willey como un chico listo que sabía las lenguas necesarias, así que Hencken me ofreció patrocinio si hacía mi tesis con esos materiales. Yo le contesté que me interesaba, pero que me habían dado una beca para ir a Cambridge y que debería ir y formarme más en serio.

Juan Manuel Vicent (JMV): Entonces te marchas a Cambridge. Háblanos un poco de tu impresión al llegar a Cambridge y las diferencias que observas entre la vida universitaria norteamericana y la británica.

AG: Desde luego es un cambio importante de vida. Uno tenía que solicitar plaza en un college y me recomendaron ir al St John's College, porque ahí estaba Glyn Daniel (Renfrew 2004) que, como director de Antiquity, era una persona conocida y amable. Cuando uno llegaba a Cambridge con una beca concedida por Harvard (u otra universidad prestigiosa) como era mi caso, te solían aceptar donde pedías porque llegabas ya preseleccionado. En 1965 St John's permanecía en el antiguo régimen: no había mujeres, se cerraba monásticamente a las 11 de la noche, etc. Me instalaron en Merton Hall ${ }^{12}$, un edificio justo fuera del recinto reservado para graduados de otras universidades, a los que no se les sometía a la disciplina monástica de la institución. En el refectorio o en clase uno estaba obligado a vestir con toga. Cambridge estaba lleno de cosas así, absurdas para un norteamericano.

JMV: ¿Qué cursos seguiste durante tu estancia en Cambridge? ¿Seleccionabas tu propio programa?

\footnotetext{
${ }_{12}$ Merton Hall, también conocido como la Escuela de Pitágoras, es el edificio civil más antiguo de Cambridge y una residencia para graduados perteneciente a St. John's College.
}

AG: Mi director de estudios era Glyn Daniel. El sistema era sencillo: el departamento tenía un programa de clases magistrales cada año en el que los profesores daban las que deseaban y tú asistías si querías. No eran asignaturas. Toda tu titulación dependía de los exámenes que hacías al final de los últimos dos años del programa. Tenías libertad absoluta para prepararlos como quisieras.

JMV: Es decir, no tenías obligación de rendir cuentas por asignatura.

AG: Exactamente. Era un sistema en el que asistías a clases magistrales y se te monitorizaba mediante tutorías. Tu director de estudios te sugería dos tutorías por trimestre. Cada semana preparabas dos ensayos de unas 10 páginas, el tutor lo leía o se lo presentabas viva voce, e ibas pasando de tema a tema. Así que era un trabajo bastante intenso. Entre ir a las clases, las horas de biblioteca para preparar los trabajos y los fines de semana escribiendo ensayos para la siguiente semana volver a empezar de nuevo, estabas trabajando todo el tiempo y aprendías, iy aprendí mucho! Era un sistema bueno para un buen alumno.

JMV: ¿Cuál era el papel del tutor?

AG: El director de estudios recomendaba y yo hacía exactamente lo que me recomendaba Glyn Daniel.

JMV: ¿Qué puedes decir sobre Glyn Daniel?

AG: Daniel era una persona encantadora, un arqueólogo completamente tradicional pero con las ideas abiertas. Le gustaba apoyar a gente con talento y conmigo fue muy amable. Además, fue un buen maestro en el sentido de que te daba bastante libertad para hacer lo que quisieses.

JMV: ¿Qué otras figuras recuerdas de tus días en Cambridge?

AG: Bueno, durante el primer trimestre hice tutorías con Daniel sobre lo que más le interesaba: arte paleolítico, megalitos, etc. También me recomendó que, para tener otras ideas, hiciese unas tutorías con Eric Higgs que por entonces no era profesor, sino el técnico encargado del laboratorio de Arqueofauna.

JMV: ¿Se percibía en aquel momento y desde allí la existencia de una Escuela Paleoeconómica de Cambridge?

AG: El profesor catedrático y director del departamento era Grahame Clark. Había escrito Prehistoric Europe: the economic basis (Clark 1952) y ya hacía bastante tiempo que había publicado el primer manual de introducción a la Arqueología verdaderamente funcionalista, Archaeology and society (Clark 1939). Aplicaba el funcionalismo a la Arqueología y lo había demostrado de manera práctica en el campo, en las excavaciones de Star Carr (Clark 1954). El profesor Clark era una persona distante que no daba tutorías, pero sí un solo curso de clases magistrales por año. Sin embargo, el ejemplo de su práctica arqueológica 
estaba ahí. Uno de sus patrocinados era Eric Higgs, que por entonces estaba preparando lo que eventualmente sería, poco después de que yo saliera, el proyecto The early History of Agriculture ${ }^{13}$, el programa de estudios donde se inventó el site catchment analysis. Higgs era una persona rara. Sus seguidores eran como una especie de secta, los higg-lets ${ }^{14}$. Pasar de Daniel a Higgs era pasar por la experiencia del Normativismo clásico a una versión radical del por entonces nuevo Funcionalismo. Higgs tenía dichos muy simpáticos. Por ejemplo, decía que los arqueólogos se habían equivocado desde el principio guardando los artefactos y tirando la tierra, cuando deberían haber hecho lo contario. Bueno, yo veía por qué decía eso.

Pero también tuve tutorías con otras personas como John Alexander (Evans 2011), John Coles (Paardekooper 2009), David Clarke... Colin Renfrew estaba recién doctorado y a punto de incorporarse a una plaza en Sheffield. En la primavera de ese año de 1966 tuve una tutoría con él, así que es posible que haya sido su primer alumno.

JMV: Esto es interesante. Muchas de las personas que has enumerado tuvieron luego relevancia en el despegue y desarrollo de la arqueología funcionalista. Renfrew, Coles, David Clarke ¿ya se movían en esa dirección?

AG: Absolutamente. Renfrew ya había pensado su reinterpretación del registro del Egeo. Su obra se publicó más tarde (Renfrew 1972) ${ }^{15}$, pero para fines de los 1960 ya estaba terminada.

JMV: Es decir, había un cierto ambiente de progresión...

AG: Sin duda. Uno estaba ahí más o menos en el filo cortante de la navaja...

JMV: ¿Y David Clarke?

AG: Desde el primer momento me llevé mal con David Clarke, pues siempre he sido bastante impertinente. En mi primera semana en Cambridge asistí a todas las

\footnotetext{
13 The apex of the palaeoeconomy school within Cambridge, however, centred around the granting of a British Academy Major Research Project entitled 'The Early History of Agriculture' in 1966. To direct this project, Clark and his management committee turned to Eric Higgs. Higgs was an experienced hill-farmer who had worked as a research assistant in Cambridge since 1956 (Outram y Bogaard 2019: 6; véase también Jarman et al. 1982).

${ }^{14}$ Sharing its cigarette fug were the pack of graduate students -the 'Higg-lets'- he was distributing around the Mediterranean lands. A smaller group of 'Clarke-lets' at the same period revolved round David Clarke, who was based outside the department (Chippindale 1994: 687).

${ }^{15}$ En palabras del propio Renfrew, My doctoral thesis could have been published in a monograph, but it was turned down by Cambridge University Press as not being what they wanted at the time. When I came to write The Emergence of Civilisation [1972] I left out the chapters in the dissertation about the west Mediterranean and the Balkans, and they were published in papers like 'Colonialism and megalithismus' [1967] and 'The origins of the south-east European Copper Age' [1970] (Harding 2009: 148).
}

clases magistrales para ver lo que hacían unos y otros. Clarke dio una revisando un artículo que había publicado en los Proceedings of the Prehistoric Society (Clarke 1962) sobre un análisis de matrices de cerámica campaniforme británica. He de decir que Clarke lo explicó con una claridad meridiana. En su Tesis había hecho una seriación que le había permitido establecer una secuencia estilística de vasos campaniformes británicos basada en los atributos que compartían. Su propuesta había sido calcular la similitud porcentual de cuántas características formales compartían dos vasos campaniformes y a base de eso construir una matriz Brainerd-Robinson de similitudes, en la que habría una escala progresiva de cambios estilísticos, y esa escala era consistente con los datos estratigráficos y contextuales disponibles. Esa era su tesis, pero -nos dice- "uno puede hacerlo al revés". De la misma manera que uno puede comparar los vasos por la cantidad de rasgos que tienen en común, uno puede comparar los rasgos por el número de vasos que tienen en común. Esto demuestra, entonces, que los rasgos que son del primer estilo tienen más vasos en común y, por lo tanto, que el enfoque funciona. Entonces yo levanto la mano desde el fondo de la sala $\mathrm{y}$, con mi más profundo acento americano, lo que es imperdonable en Cambridge, le pregunto: "Dr. Clarke, comprendo el análisis estilístico comparando rasgos pues, al fin y al cabo, cada vaso se hace en un cierto momento y la gente que hace esos vasos va a tener más ideas en común cuanto más cercanos en el tiempo estén. Un vaso se hace primero y otro será el último, pero no entiendo esto de los rasgos. Tendrá que haber un rasgo que sea el último. ¿Qué hace entonces? -digo yo, y esta es la impertinencia imperdonable- ¿desaparece como la sonrisa del Cheshire cat?". Y entonces toda la clase se echó a reír.

JMV: Mal comienzo con David Clarke.

AG: Se puso furioso. Pero, sin embargo, es evidente que yo tenía toda la razón... Ya me había dado cuenta que eso del formalismo, en forma del análisis de atributos como el que proponía Movius, era una cosa un poco rara. Pero esto ya... era demencial. Luego pasé a recibir tutorías con Clarke y, claro, se acordaba perfectamente de mí y me hizo la vida un poco imposible. Pero eso tampoco tuvo consecuencias dado que las tutorías no se evalúan, están para que uno aprenda.

JMV: ¿Cuál era, en aquel momento, la presencia de Childe en la arqueología británica?

AG: Era reconocido como la persona más importante que había practicado la Prehistoria en Gran Bretaña y sus últimos trabajos todavía eran relativamente recientes. Childe había muerto en 1957. La última edición del Dawn of European Civilization, había sido publicada hacía sólo ocho años. La reedición de Man makes himself era del 1951. Sus influyentes obras eran recientes y, evidentemente, era la persona a partir de la cual uno debía empezar a trabajar. 
JMV: ¿No había, entonces, ninguna especie de damnatio memoriae por sus inclinaciones ideológicas, digamos, sospechosas en tiempos de Guerra Fría...?

AG: No, en absoluto. Para Daniel el marxismo de Childe era una especie de extravagancia, pero consideraba que Childe era el autor de la primera gran síntesis de la Prehistoria europea y que sus libros de síntesis eran fundamentales.

JMV: Y, de alguna manera, ¿la 'secta' de Higgs se reconocía como deudora de Childe?

AG: No, no creo que directamente. Childe estaba presente como una figura importante pero en segundo plano: no tenía seguidores directos. Es evidente que, por ejemplo, una persona como Grahame Clark había recibido la influencia directa de Childe, pues había sido alumno a finales de los años 20, cuando Childe escribía un nuevo libro importante cada año. Clark estaba al inicio de su formación académica y quizás en parte por eso se dedicó a la economía prehistórica de Europa desde fundamentos materialistas, aunque no con un enfoque marxista.

JMV: Es decir, que lo interiorizó a partir del programa de Childe pero no trató de conectarlo con las implicaciones teóricas del mismo. Realmente, ¿Childe no dejó un programa explícito que pudiera hacer escuela?

AG: No, sin duda. Además es curioso pues, que yo sepa, Childe nunca tuvo una escuela directa. Al principio tuvo un puesto en Edimburgo, más o menos marginal para la arqueología británica y luego el de director del Instituto de Arqueología en Londres con trabajos administrativos, etc. Realmente fue un gran sabio, pero nunca...

JMV: ...nunca tuvo alumnos directos, ni creó un programa que tuviera seguidores.

AG: No, no formó a gente. Como ejemplo contrario, Don Américo tuvo toda una serie de personas que estudiaron y se formaron con él en Princeton, como mi padre, Edmund King, Russell Sebold y otros más que se consideraban discípulos suyos. Yo no creo que haya una generación de académicos que se considerasen discípulos directos de Childe. Era una persona muy tímida.

JMV: Entonces, era una figura más bien simbólica, por así decir.

AG: En la introducción del libro que editó Bernard Wailes (1934-2012) en memoria de Childe, en el que yo contribuí con un artículo (Gilman 1996), Wailes (1996: xi) deja claro que en los años 50 era una presencia querida, reconocida y muy leída, pero extrañamente distante ${ }^{16}$.

\footnotetext{
16 Our impression was that he was rather aloof, or perhaps different or perhaps shy (Wailes 1996: xi).
}

JMV: Por lo tanto, si no lo entiendo mal, la figura de Childe en Inglaterra no tiene nada que ver con lo que fue, por ejemplo, en México, donde la parte "extravagante" de Childe fue justo la que tuvo un gran impacto en la generación de Armillas, Palerm, Lorenzo, etc (Olivé Negrete 1988) ¿Y en los EE.UU.? ¿Cuál era el impacto de Childe en aquel momento?

AG: Se le reconocía como un gran sintetizador y lógicamente en discusiones de la Revolución neolítica su teoría del oasis era una propuesta fundamental que tenía que ser contrastada. Childe había recibido todos los honores posibles en las universidades americanas. Cuando la Universidad de Harvard organiza un simposio en 1936 para celebrar los 300 años de su fundación invita a los mayores representantes de cada disciplina a dar una conferencia. La persona invitada como prehistoriador es evidentemente Childe ${ }^{17}$. En ese sentido, una persona como Adams ${ }^{18}$ siempre se refiere a su lectura de Childe, a pesar de que nunca estudió con él. Sin duda tenía la edad como para haberle conocido, pues Adams se educó e hizo su carrera inmediatamente después de la guerra. Es decir, quizás asistió a alguna de sus conferencias y se acercó a saludarlo, pero... ${ }^{19}$

PDR: Una pregunta dentro de este contexto: ¿cuándo reconoces la importancia del marxismo de Childe?, ¿en qué momento empiezas a pensar que el marxismo es una forma de interpretar el mundo útil para tu propia disciplina?

AG: No puedo decirte exactamente. Yo evolucioné, y está claro que ya entrado el año 1971 o 1972 tenía ya las ideas claras en ese sentido. Entre una cosa y otra me di cuenta de que todos esos planteamientos de Childe tenían antecedentes claros, hasta cierto punto ya declarados, como sucedía con otros, como Eric Wolf. Entonces empecé a leer un poco más y advertí que se trataba de toda una escuela histórica en la que no solo está Marx, sino todo un gran grupo de historiadores, de economistas, etc. Es decir, fue por entonces cuando me di cuenta de que el marxismo era una corriente que debía tener presente... pero yo nunca he sido un teórico en ese sentido.

JMV: No sé si hay algo más que añadir sobre tu experiencia en Cambridge.

\footnotetext{
17 As part of its $300^{\text {th }}$ birthday celebrations in 1936, Harvard University convened a symposium entitled "Independence, Convergence, and Borrowing in Institutions, Thought, and Art". On that occasion, V. Gordon Childe, widely esteemed as one of the greatest prehistorians of the twentieth century, offered what he entitled "Europe and the Near East: A prehistorian's interpretation of diffusion" (Potts 2012: 106).

${ }_{18}$ Robert McCormick Adams (1926-2018), https://siarchives.si.edu/ history/robert-mccormick-adams

${ }_{19}$ Yoffee (1997: 401) precisa el contacto: Adams spent an entire day with Childe in London in 1956, on the eve of Childe's return to Australia.
} 
AG: Bueno, como te decía, Cambridge era un sitio rarísimo, un mundo de costumbres medievales. Por ejemplo, cuando uno se gradúa en Cambridge debe vestirse una toga especial para recibir el título de rodillas delante del canciller, que impone sus manos sobre ti y te declara bachiller. Me escapaba inmediatamente al final del curso para ir a países civilizados.

PDR: ¿Hay algún compañero tuyo de esa época, compañero del curso, que recuerdes o con el que hayas tenido amistad?

AG: Es un punto muy significativo. La respuesta es no y la razón es que no formé parte de ningún equipo de trabajo de campo organizado desde Cambridge. Había, por ejemplo, quienes excavaban con Higgs en Grecia, pero yo todos los veranos hacía mi propio trabajo de campo. Pero, además, los alumnos no se hablaban entre sí. El fin del tripos era pasar por unos exámenes finales de cuya nota dependía todo tu futuro. En mi caso no tenía mucha presión, pues para cuando me presenté al examen ya me habían dado una beca para el año siguiente en Harvard. Quise hacer los exámenes bien, por supuesto, pero la nota no era esencial para mi futuro. La mejor nota que uno puede obtener en este examen es un First, pero eso no ocurre todos los años. De las 20 personas que pueden estar haciendo el examen de Prehistoria, quizás una consiga un First. Los alumnos que reciben un 2:1, un Upper Second, tienen posibilidades profesionales. Si recibes un 2:2 o un Third debes dedicarte a otra cosa. El 2:1 es una nota respetable y hay toda una serie de arqueólogos importantes que la han obtenido, como Glynn Isaac, jel mayor paleolitista del siglo XX! Este final, en el que te lo juegas todo, se hace en siete exámenes de tres horas cada uno durante tres días y medio seguidos: mañana-tarde, mañana-tarde, mañana-tarde y mañana.

JMV: ¡Qué horror!

AG: Toda tu vida depende de eso y lo profundamente perverso del sistema, es que lo que cuenta para recibir un First no es tanto dominar la materia necesaria, sino ser brillante, tener ideas. Por lo tanto, si tienes una buena idea te la callas, porque si dos personas tuvieran la misma idea jentonces ya no sería brillante!

JMV: Es un sistema de todos contra todos.

AG: Sí, así es, y como consecuencia la gente no se hablaba. Bueno, la gente era amable y se trataban entre si, pero eso de estar ahí discutiendo sobre arqueología con otro... ¡No! Tú estabas ahí con los naipes pegados al pecho, lo cual es perfectamente antieducativo. En la sección NBI (Neolithic-Bronze-Iron) pasas por dos exámenes de cada periodo y uno sobre un tema particular conocido de antemano (en mi año el megalitismo). Cada examen consta de diez preguntas de las cuales debes contestar cuatro. Muchas de esas preguntas permiten que uno demuestre lo que sabe y escogí esas sistemáticamente. Es difícil, sin embargo, ser brillante en preguntas del tipo "haga un resumen de la secuencia neolítica de Dinamarca". Daniel me dijo después que solo una de mis respuestas había sido considerada "brillante" y jera precisamente una de las cosas sobre las cuales sabía menos! Me acuerdo bien de la pregunta: ¿qué era más importante en Mont Lassois, el hierro o el bronce? Sabía que Mont Lassois era el oppidum vecino a Vix, pero poco más, pues la Edad del Hierro no era lo mío. Pero pienso en Childe ${ }^{20}$ y me lanzo a la especulación: "evidentemente, es el hierro, pues el hierro hace despegar la productividad agrícola que es la base que sustenta todo el comercio que crea...". ¡Sin datos! Bueno, pues eso se supone que es ser brillante. Recibí un 2:1 y Daniel quedó algo decepcionado conmigo.

JMV: En definitiva, no has mantenido relación con ninguno de tus compañeros de Cambridge.

AG: He mantenido contacto con dos compañeros, ambos americanos y especialistas en el Paleolítico: Mary Pohl y Paul Ossa. Evidentemente, tengo amigos que pasaron por Cambridge después del 1967, como Richard Harrison (compañero mío en la etapa siguiente de Harvard) y Bob Chapman.

JMV: Cuando terminas en Cambridge itienes una idea de qué es lo que quieres hacer?

AG: Sí. Durante la última primavera en Cambridge acepté una beca de cuatro años en Harvard. También recibí una de la Universidad de Chicago, donde quizás debiera haber ido, pero me decidí por Harvard por dos razones. Primero porque me encantaban la biblioteca del Peabody Museum y la bibliotecaria. Miss Currier (Sabloff 1974) era un recurso enorme. Había hecho amistad con ella en mi época de estudiante de Movius. Conocía muy bien la biblioteca, que contaba con una colección arqueológica y antropológica estupenda. Pero, en segundo lugar, porque Hencken pasó por Cambridge para verme y ofrecerme otra vez que hiciese mi doctorado sobre el Neolítico de Tánger. En esa ocasión me pareció prudente decirle que iría a ver las colecciones en detalle para así decidir de una manera informada. Yo sabía que ese trabajo venía acompañado de la garantía de publicar la tesis como una de las monografías del Bulletin of the American School of Prehistoric Research, que llevaba el propio Hencken.

Cuando volví a Harvard me dieron un espacio de laboratorio, saqué las colecciones, las miré, leí un poco las cosas y me pareció que el material era el resultado de una de las mejores excavaciones que jamás se había

${ }^{20}$ AG. Cheap iron democratized agriculture and industry and warfare too (Childe 1964 [orig. 1941]: 191). 
hecho en el norte de África. Estaba todo bien ordenado, bien organizado. Lo que había hecho Hencken estaba bastante bien, sobre todo comparado con lo que habían hecho algunos aficionados a la arqueología como el padre Koehler, un dominico que había estado en Tánger, o el señor Jodin... Hencken tenía colecciones de fauna (ya identificada por Camille Arambourg), lítica, etc... Era una arqueología perfectamente respetable. Dije que sí y me dediqué a eso. Como protegido de Hencken pude hacer mi tesis de forma independiente.

Como además era un buen alumno, pude recibir los apoyos necesarios.

JMV: Es decir que vuelves de Cambridge a Harvard con un proyecto ya concreto de trabajo.

AG: Sí, pero tenía que hacer los cursos de doctorado y pasar los exámenes generales antes de dedicarme a la tesis. Recibí buenos consejos, en particular del que había sido mi teaching fellow y que ahora estaba acabando su tesis, Harvey Bricker (2007), paleolitista y alumno de Movius. Le pregunte cuál era la asignatura de doctorado que, si hacías bien, te dejaban en paz después y me aconsejó que me apuntara al seminario sobre la historia de la teoría del parentesco de David Maybury-Lewis. Había sido alumno de Rodney Needham en Oxford. La clase que daba empezaba con Morgan y acababa con el análisis componencial de sistemas de parentesco como entramados lingüísticos, pasando por Radcliffe-Brown, Lévi Strauss, Mauss, etc. Aprendí mucho. Era una asignatura bastante selectiva. De los treinta que se apuntaron, cuatro o cinco recibieron $A s$ y yo fui uno de ellos. El otro buen consejo que me dio Bricker tuvo repercusiones después. Para modernizarse, el Departamento de Antropología en Harvard había introducido una sección de estadística en el examen general de Arqueología y de Antropología física que uno debía hacer al final del tercer cuatrimestre. Yo sabía que los profesores de arqueología-Movius, Willey, Williams, Lamberg-Karlovsky, Patterson- no eran precisamente expertos en el tema. Le pregunté a Bricker quién sería la persona que evaluaría el examen. Me contestó que lo único que podrían hacer era pedírselo al profesor no numerario que se encargaba de la Antropología física aplicada, el médico Albert Damon (Annals of Human Biology 1974), que daría una asignatura sobre el tema el semestre siguiente. Aunque la antropometría no era un tema de mi mayor interés, me pareció prudente apuntarme a la clase. Se lo comenté a Mary Pohl, que conocía de mi etapa en Cambridge, y ella a su vez se lo comentó a Martha Prickett, su compañera de habitación. Los tres fuimos los únicos arqueólogos en la clase (que, en efecto, tenía un elemento de estadística) y cuando llegó el examen general solo nosotros aprobamos la sección de estadística. Las preguntas no eran difíciles: uno tenía que identificar el test apropiado para el tipo de problema planteado. El caso concreto, que nosotros tres pudimos contestar y los otros no, era comparar la edad de menarquía de madres e hijas. Decir lo evidente, un t-test entre las dos series, era incorrecto: se debería usar un paired means test, pues cada madre se puede emparejar con cada hija y entonces reducir los grados de libertad correspondientemente. Eso nos lo había explicado Damon y bueno...

JMV: Sí, pero es una pregunta bastante capciosa.

AG: Bueno, sí. Martha, Mary y yo pasamos y todo el resto de la promoción cateó. Eso representaba un problema considerable, porque para empezar a hacer tu proyecto de tesis tenías que haber completado con éxito el examen. Podías repetir una parte pero eso te costaba un año. En fin, tras eso me fui al campo un año y volví en febrero de 1971.

PDR: Ya habías estado en Tánger...

AG: Había estudiado colecciones en Tánger, Rabat, Tetuán, Orán, Argel, el Musée de l'Homme y en varios museos de la península ibérica que tenían colecciones neolíticas.

En la primavera de 1971 el departamento había fichado a George Cowgill (1993), que sí era un experto en estadística aplicada a la arqueología, para dar una asignatura sobre el tema. Naturalmente, Cowgill tenía ahora delante a todos los numerosos estudiantes que no habían pasado aquel examen y tenían que hacer la asignatura de nuevo, y estaba desesperado porque le hacía falta un ayudante, un teaching assistant, para corregir los ejercicios. Yo no sabía prácticamente nada de estadística, pero como había pasado el examen y Pohl y Prickett no habían vuelto del campo, pude suplir esa necesidad. Además de ser un gran sabio y un profesor de gran claridad, George era una persona muy amable y muy paciente. Yo asistí a sus clases, corregí todos los ejercicios (evidentemente bajo su dirección) y así aprendí bastante estadística. George fue un muy buen maestro mío.

JMV: O sea que a esas alturas ya tenías las armas que luego ibas a emplear en el combate, y me refiero al site catchment analysis y a la idea de que la estadística puede ser una forma razonable de plantear problemas arqueológicos.

AG: Bueno, estaba desarrollando las ideas, pero sí, ya había leído las cosas necesarias para hacerlo.

JMV: ¿Influye esto en algo al optar por el tema de tesis?

AG: Mi tesis fue esencialmente un proyecto práctico (Gilman 1975). Era importante porque establecía mis credenciales. Lo que hice fue una arqueología perfectamente normal, secuencial, tipológica, comparativa...

JMV: En cualquier caso, esto te lleva a trabajar en el Viejo Mundo y concretamente en el Mediterráneo 
donde, supongo, ves algo que lo hace preferible a Mesoamérica o al norte de Europa.

AG: Comparado con el norte de África, el sur de Europa era un territorio arqueológica y económicamente desarrollado. Podría haber seguido trabajando en Marruecos, pero hace cincuenta años no había arqueólogos marroquíes que se interesaran en la Prehistoria y no me interesaba continuar en plan colonial. La Arqueología debe hacerse de forma colegiada y sabía que en España podría tener colegas que me ayudarían. Habiendo sido alumno en Ampurias, ya conocía un buen número de personas. Este mismo jueves iré a la sesión en memoria de Juan Zozaya ${ }^{21}$, con quien me encontré en Ampurias en el año 1962.

JMV: Luego hablaremos de eso. Pero, más que a los motivos prácticos por los cuales emprendiste este trabajo, me refiero a si estudiar la secuencia neolítica en Tánger te da alguna idea sobre cómo continuar después.

AG: Sí, pero más bien por una casualidad. Aparte de un capítulo para Chronologies in Old World Archaeology (Gilman 1992), mi trabajo doctoral no tuvo consecuencias posteriores. Pero en el curso del trabajo para la tesis me di cuenta de lo que era el Sureste español. En enero de 1971 Benedicte y yo tomamos un tren de Granada a Valencia (había estado repasando el material neolítico de La Carigüela e iba ver el de Cova de la Sarsa y Cova de l'Or, para abordar el trabajo comparativo con el Neolítico del norte de África). Este tren pasaba por Guadix y Baza, bajaba el río Almanzora hasta Huércal-Overa y seguía hacia Lorca hasta llegar a Valencia. Llegamos a la estación de tren de Granada todavía en la oscuridad de una mañana fría y lluviosa de enero. Nos sentamos en el compartimento y nos dedicamos a leer nuestras novelas, creo que yo estaba leyendo Cien años de soledad por entonces. La primera parada era Guadix. Miramos por la ventana; era ya de día y hacía un sol espléndido, y ahí, aparcado al lado del tren, había un vagón en el que ponía Santa Fe Railroad. Estaban rodando una película del Oeste. A continuación seguimos el viaje y por la ventana se veía desierto y más desierto. Yo, por supuesto, ya había leído sobre la Cultura de Almería, Los Millares y El Argar, ipero no me había dado cuenta que era un desierto! Después vi que sí, que Juan de Mata Carriazo había hecho algún comentario al respecto (Carriazo 1947). Evidentemente, también estaba presente en la obra de los Siret, pero ¡nadie lo había puesto en valor! Rápidamente me di cuenta de que aquí había un tema de trabajo.

\footnotetext{
${ }^{21}$ Museo Arqueológico Nacional. "Homenaje a Juan Zozaya StabelHansen”. Jueves 21 de noviembre 2019.
}

JMV: O sea que, efectivamente, tu interés por la Prehistoria ibérica es un resultado colateral de tu trabajo en la secuencia de Tánger, pero, sobre todo, es un descubrimiento empírico.

AG: Había recibido una buena formación y sabía que las grandes civilizaciones se habían desarrollado en condiciones donde el regadío había sido importante. Me daba cuenta a partir de mi lectura de Childe en Man makes himself de que en todo el Próximo Oriente las gentes habían invertido su trabajo en la tierra y no abandonarían con facilidad las inversiones que ellos mismos habían creado $^{22}$. ¡Ahí está!

JMV: Por lo tanto, de alguna forma, esa experiencia activó un pensamiento que tus lecturas y reflexiones habían creado ya.

AG: Sí, jera todo evidente! Cuando germinó mi idea del proyecto en el Sureste en ese viaje en tren, lo primero que me hacía falta era leer todo lo que se había publicado sobre la Arqueología del Cobre y del Bronce en la región, una bibliografía que todavía no había consultado de una forma sistemática. Por otra parte, debía hacer lo mismo con toda la literatura que existía sobre los sistemas de regadío y las relaciones sociales y de propiedad que dependen de ellos: Robert McC. Adams (1966), Thomas Glick (1970), Karl Wittfogel (1957) y otros muchos que habían publicado sobre el asunto.

Pero primero tenía que acabar y entregar mi tesis, lo cual hice en junio de 1973. Ese verano lo íbamos a pasar en la casa de mis padres en Nerja y aproveché la ocasión para llegar un par de semanas antes que ellos e irme con el coche que tenían ahí a visitar los yacimientos del Sureste. Nunca había estado en Los Millares, El Argar, El Gárcel... Los tres años siguientes los pasé en parte convirtiendo mi tesis en publicaciones (Gilman 1974, 1975, 1976), pero fundamentalmente dedicado a las lecturas necesarias. $\mathrm{Y}$ a base de ellas preparé un primer esbozo de mis propuestas.

PDR: Terminas tu trayectoria en Harvard en el 72 y vas a la University of Wisconsin, Oshkosh (UW Oshkosh) ¿En qué momento te incorporas al Departamento de Antropología de la California State University, Northridge (CSUN), donde desarrollas el resto de tu carrera profesional?

AG: En el otoño de 1972 el trabajo para la tesis estaba prácticamente hecho, pero tenía que escribirla, rellenar el guión, por decirlo así. Podría haberme quedado en Cambridge y, quizás, obtener un puesto al año siguiente, pero ya estaba claro que el gran boom universitario de la postguerra había concluido. Ya no iban a entrar más baby boomers en las universidades: si

\footnotetext{
22 The soil, thus hardly conquered was a sacred heritage: no one would willingly abandon fields so laboriously created (Childe 1953: 88).
} 
buscabas un puesto, mejor encontrarlo cuanto antes. Tuve entrevistas en un par de sitios y en la reunión anual en Nueva York de la American Anthropological Association me ofrecieron una plaza en UW Oshkosh ${ }^{23}$. Éramos 45 doctorandos de Antropología en mi promoción de Harvard. Más o menos la mitad acabó. La otra se quedó por el camino por motivos varios, ipero veintitantos sí acabaron! Esto estaba sucediendo en todas las universidades norteamericanas del momento y era obvio que ya no había plazas para todos ellos. De hecho, yo estuve en Oshkosh un año como instructor. Me despidieron por razones económicas en el primer semestre, sin siquiera evaluarme. Me ofrecieron de nuevo el puesto antes de que me fuera, pero ya había encontrado algo en California y rechacé la oferta. En Oshkosh acabé la tesis y preparé todas las clases que seguiría enseñando durante 40 años más. Llegué a la CSUN en 1973. Los primeros dos años me contrataron anualmente y en 1975 me pasaron al tenure track como Assistant Professor.

PDR: ¿Tenías alguna conexión con Northridge o con alguna de las universidades de California?

AG: Sí, tenía dos conexiones. La primera vino a través de Michael Moseley (Nuzzo 2006), un amigo mío de Harvard. Trabajaba en el yacimiento peruano de Chan Chan, cerca de Trujillo, y la co-directora era una profesora en Northridge, Carol Mackey, que se había formado en Berkeley.

La segunda vino a través de Ted Carpenter $^{24}$, un primo segundo de mi padre (sus madres eran primas hermanas). Aunt Barbara tenía una casa al lado de la de mi abuela, Martha Rogers en Gull Lake (Michigan), donde toda una serie de primos habían comprado casas de verano. Ted tendría cinco o seis años menos que mi padre, pero se habían criado juntos. Él fue el fundador del Departamento de Antropología en Northridge. Carpenter era especialista en el arte de los Inuit y un colaborador de Marshall McLuhan ${ }^{25}$, y vino desde la Universidad de Toronto para organizar un programa dedicado a la Antropología del arte. Salió de Northridge en 1966 o 1967, en circunstancias difíciles, pero en el departamento todavía había un par de personas que él había fichado y que habían sobrevivido a la purga que la universidad hizo para liquidar su programa.

\footnotetext{
${ }^{23}$ AG 1972-1973: UW Oshkosh: Instructor, Department of Sociology, Anthropology, and Social Work. Courses taught: "General Anthropology", "Old World Prehistory", "Museum Methods", "Method and Theory in Archaeology".

${ }^{24}$ Edmund "Ted" Snow Carpenter (1922-2011) https:// edmundsnowcarpenter.com/2016/08/16/first-blog-post/ (consulta 08-042020).

${ }^{25}$ Herbert Marshall McLuhan (1911-1980), The Official Site for the Estate of Marshall McLuhan https://marshallmcluhan.com (consulta 0804-2020).
}

Conseguí el puesto en 1973. Para dar una idea de la situación, cuando me incorporé era el número $20 \mathrm{a}$ tiempo completo en un departamento con 24 plazas, de las que 4 estaban divididas entre $\mathrm{PNNs}^{26}$. La siguiente persona nombrada a tiempo completo en ese departamento llegó en 1991, 18 años después, cuando quedaban sólo 12 plazas. Es decir, cogí el último tranvía...

\subsection{El Sureste de la península ibérica y la Mancha occidental}

JMV: Volviendo a tu trabajo en la península ibérica, tu artículo de Dialectical Anthropology de 1976 es anterior al diseño y realización práctica del proyecto...

AG: Sí, es una apuesta, una especulación sobre lo que creía que había sucedido en el pasado.

JMV: Es decir, es una propuesta teórica cuya consecuencia práctica es el planteamiento del proyecto. $\mathrm{Si}$ no he entendido mal, la reflexión sobre tu propia experiencia al atravesar el Sureste desde la perspectiva teórica que se expone en el artículo de 1976, te lleva a la formulación positiva de preguntas al registro arqueológico, preguntas sobre lo que debería observarse en el registro si tus planteamientos fueran acertados. El proyecto se plantea para resolver esta cuestión.

AG: Sí. En 1967 Renfrew había publicado su clásico "Colonialism and megalithismus" donde ya afirmaba que no era posible que todo viniese del Oriente pues los fenómenos supuestamente orientales eran anteriores en la península ibérica. Es decir, ve que las fechas C14 de Los Millares demuestran que era anterior a Chalandriani. Realiza estas afirmaciones como argumentos contra la explicación difusionista del desarrollo prehistórico en Europa occidental, pero no propone una alternativa para el caso concreto del Sureste de la península ibérica. Yo, obviamente, conocía su trabajo: creo que se refirió a su interés en el Sureste cuando hice tutorías con él. Así que cuando inicié ese viaje en 1971, ya sabía que quedaba una explicación pendiente. En paralelo, el propio Renfrew propuso a Chapman abordar una explicación de este fenómeno, y Bob hizo más o menos lo mismo que yo: visitar el campo y hacer una reflexión teórica e interpretativa.

En 1975 entregué una versión previa de lo que sería mi artículo de Dialectical Anthropology a mi antiguo maestro, Glyn Daniel, que para entonces acababa de suceder a Clarke como Disney Professor ${ }^{27}$. Daniel me contestó, muy amablemente, diciéndome que era muy interesante pero que un doctorando de su

\footnotetext{
${ }^{26}$ Profesores No Numerarios de la universidad española a fines del franquismo.

${ }_{27}$ Daniel sucedió a Clark en 1974 y dirigió Antiquity durante 27 años (1958-1985).
} 
departamento estaba trabajando en algo muy similar y que le parecía una deslealtad publicarlo. "Seguro que encontrarás otra revista", me dijo.

Por entonces estaban solicitando artículos de temas arqueológicos para el primer número de Dialectical Anthropology, así que hice unos pequeños ajustes teóricos y lo publiqué.

En 1977 entregué una primera propuesta de proyecto a la National Science Foundation (NSF) que me rechazaron, pero la National Endowment for the Humanities (NEH) me financió un estudio piloto ese verano. Eran 5.000 \$, una cantidad nada insignificante para aquel entonces. Pude alquilar un coche, pagar las dietas de campo y pasarme dos meses visitando los yacimientos que contaban con datos paleoeconómicos, fundamentalmente los estudios de Angela von den Driesch (1972) y sus colegas del grupo de Munich en el Cerro de la Virgen y otros trabajos similares. Buscaba datos arqueológicos para anclar mi proyecto.

Ese verano tuve que inventarme cómo hacer el site catchment analysis. La presentación de los métodos de Higgs y Vita-Finzi (1972) era bastante esquemática y la práctica concreta debía ajustarse a las condiciones reales de los paisajes particulares en estudio. Con los resultados de ese verano y del siguiente (financiados por la Sociedad de Estudios y Publicaciones, SEP) (Anes y Gómez Mendoza 2009) pude preparar una nueva propuesta que obtuvo la financiación combinada de varias instituciones. La matching grant de la NEH fue la pieza clave. Ellos me prometieron unos $30.000 \$$ si obtenía una cantidad igual en otra parte, y ese resultado positivo me permitió obtener el apoyo de la Fundación Juan March (cuyo asesor resultó ser Manuel Fernández Miranda), la Fundación Universitaria Española y la Tinker Foundation.

Con esa combinación de recursos pude obtener la financiación completa, lo que me permitió comprar fotos aéreas, pagar las dietas en el campo y, sobre todo, fichar a Steve Wise como becario post-doctoral para realizar el aspecto geomorfólogico del trabajo de campo que había diseñado John Thornes. John salió al campo con nosotros en dos ocasiones, pero el que estuvo al pie del cañón fue Wise. Steve trabajó bien, aunque sufrió mucho en el campo y finalmente dejó la Geografía por la Informática.

M. $^{\mathrm{a}}$ Isabel Martínez Navarrete (MIMN): ¿Cómo conociste a Thornes?

AG: Una de las críticas más serias a mi primer proyecto fallido de la NSF en 1977 fue que no había tenido en cuenta cómo la erosión en el Sureste podría haber cambiado el paisaje y que mi proyecto debería considerar ese factor.

Yo tenía mis razones para pensar que ese no era un problema grave y por eso no lo había incluido. Mi argumentación era la siguiente: yacimientos de distin- tos periodos, como El Argar, La Gerundia o El Gárcel estaban separados por barrancos. Si todo eso hubiese sido una plataforma continua no se distinguirían por épocas, luego los barrancos ya debían estar cuando se ocuparon esos lugares. Esas eran parte de mis razones, pero las críticas de los asesores de la NSF eran razonables y, en principio, abordables.

La CSUN tenía un excelente Departamento de Geografía así que fui a pedir consejo a Bob Howard ${ }^{28}$, que era geomorfólogo. Él acababa de recibir un libro precisamente sobre ese tema, cuyo autor era John Thornes (1976), profesor en la London School of Economics $(L S E)$. Me dijo, "léelo, a ver lo que te parece". Cuando lo leí me pareció claro que Thornes trabajaba sobre sistemas modernos, no como Karl Butzer (Mathewson 2017), su gran oponente, que miraba el paisaje actual y hacía interpretaciones directas sobre el pasado. Así que cuando empecé el trabajo en 1977 pasé primero por Inglaterra con la intención de leer la tesis de Bob Chapman ${ }^{29}$ y pedirle consejo a Thornes. Pasé por la librería de la LSE, compré su libro y me acerqué a su despacho. Llamé a la puerta, ahí estaba y ahí me recibió. Yo le pedí consejo sobre cómo abordar el problema y Thornes se interesó. Me comentó que siempre había querido tener un marco temporal más profundo, así que estaría encantado de colaborar en el proyecto. ¡Así de fácil! ¡Como acercarse a la más hermosa del baile y que baile contigo! Fue estupendo, un buen colega y una persona infatigable, con una gran energía. Nos llevamos muy bien.

JMV: Por lo tanto, cuando ocurrió tu encuentro con Thornes en 1977, puede decirse que el diseño del proyecto quedó completado, al incluir estos aspectos.

AG: Sí, presenté el proyecto revisado en el otoño de 1978 y me lo concedieron para el periodo 19791980.

Ese junio de 1977 también fui a ver a Bob Chapman. Ambos tuvimos la inteligencia de decidir ser amigos en vez de rivales. Como he dicho, yo había estado antes en Cambridge unos días y había aprovechado para leer su tesis. Había párrafos enteros en los que la secuencia de nuestros pensamientos era idéntica. Obviamente nos habíamos formado en la misma cantera y, tratando el mismo problema, llegábamos a conclusiones similares. Bob era, por entonces, un funcionalista mucho más optimista que yo: creía que los sistemas funcionaban. Yo tenía mis dudas al respecto, pero decidimos hacernos amigos. Sin duda fue una

\footnotetext{
${ }^{28}$ Robert Howard (1940- ) https://www.csun.edu/social-behavioralsciences/geography-environmental-studies/emeriti-faculty (consulta 0804-2020).

${ }^{29}$ R. W. Chapman. Economy and society within later prehistoric Iberia: a new framework. Unpublished $\mathrm{PhD}$ thesis. University of Cambridge, 1975.
} 
buena estrategia pues, entre otras cosas, a mí me enviaban sus solicitudes de financiación y a él las mías. $\mathrm{Su}$ colaboración con Vicente Lull y su equipo de la Universidad Autónoma de Barcelona fue un gran éxito.

PDR: En 1974 organizas con Phil Kohl la sesión sobre marxismo y arqueología en la conferencia de la American Anthropological Association (AAA) de México y en 1976 despliegas ya un pensamiento abiertamente marxista en tu artículo de Dialectical Anthropology (a propósito, sin citar a Marx). ¿En qué momento se produce este cambio hacia posiciones abiertamente marxistas?

AG: Bueno, Marx no dijo nada sobre la prehistoria del Sureste de España.

PDR: ¿En qué momento entonces haces esta transición hacia un marxismo explícito?

AG: Mi tesis era sobre el Neolítico del Magreb, un periodo y lugar en el que la cuestión de las diferencias de clase no surge. Es un mundo de un Neolítico de cerámicas impresas y post-impresas en el que un modelo funcionalista genérico es suficiente para explicar la variabilidad del registro. No hay que suponer diferencias agudas de propiedad o de clase. En consecuencia, pude hacer un trabajo fundamentalmente tradicional, tratando de construir de una manera formal la secuencia del norte de África, basada en las estratigrafías de Hencken y la comparación con otros sitios. Hice un trabajo normal y corriente de arqueología histórico-cultural, lo que también es un armazón necesario para cualquier otro, pues sin esas periodizaciones no podemos hacer nada: tenemos que saber ordenar las cosas en el espacio y en el tiempo. La tesis es un trabajo que me permitió, como decimos, to get the foot in the door.

Mientras, leía la literatura sobre el regadío y sobre sistemas de propiedad y reflexionaba sobre las obras de Childe, Wittfogel y Adams. Todos tenían cosas que decir cuya relación con un pensamiento marxista me parecía evidente. ¡No es que no hubiese leído $E l m a-$ nifiesto comunista en mi juventud! Había recibido una buena formación. Supe conectar las lecturas y establecer las relaciones que me parecían evidentes.

JMV: En 1981 publicas tu artículo en Current Anthropology, cinco años después del de Dialectical Anthropology. El trabajo en el Sureste iha corroborado o modificado tus primeros puntos de vista o este artículo es, simplemente, una reexposición de los mismos?

AG: Creía que mi artículo de Dialectical Anthropology no había tenido la repercusión necesaria, al ser un caso de estudio del Sureste de España publicado en una revista nueva y no muy consultada. Además, cada vez estaba más convencido de que ese positivismo panglosiano, según el cual todo está bien en este mundo, era fundamentalmente erróneo y que uno debía tener en cuenta los intereses contradictorios de los diferentes segmentos sociales, etc. Pensé que debía ampliar el campo de fuego, por decirlo así, y presentar algo donde pudiera tener un impacto mayor. Pero las ideas básicas son las mismas.

JMV: Entonces, aparte del deseo de mejorar la visibilidad de tus puntos de vista, de alguna manera te impulsa también el hecho de que Chapman y otros ya estén formulando explícitamente lo que has llamado "tesis panglosianas" sobre los comienzos de la desigualdad social.

AG: Me parecía que debía argumentar contra toda esa visión panglosiana, que en realidad es una constante en la literatura sobre el desarrollo de la complejidad y es parte de los "sentidos comunes" de esa "Nueva Arqueología". A mí me parecía poco realista, no correspondía con cómo funciona el mundo. Así que amplié el marco geográfico y traté de ponerlo en un contexto europeo, dirigiendo mi crítica sobre todo a las tesis de Renfrew (1972) en su gran libro sobre el Bronce del Egeo. Me ayudó mucho tener como colega a Tim Earle, que había llegado a la University of $\mathrm{Ca}$ lifornia, Los Angeles (UCLA), el mismo año que yo a CSUN, en 1973. Él había tenido la misma evolución en su tesis sobre Hawai (Earle 1978). Lo había fichado Marshall Sahlins, por entonces profesor en Michigan, para hacer una arqueología que reconstruyera los sistemas de producción agrícola en Hawai. La idea era darle un sentido temporal a la cuestión de la redistribución, a esas jefaturas "redistributivas" y "buenas" que defendía Sahlins (1958). Tim se había encontrado con un registro que demostraba que había jefes y siervos y que los intereses de los jefes y los de los siervos no se correspondían. Hay toda una serie de personas que empiezan a cuestionar estos principios panglosianos más o menos a la vez. Está Tim en Hawái, pero también Elizabeth Brumfiel (Robin 2014), también salida de Michigan que, ante el mundo azteca, se da cuenta que no es creíble que semejante sistema sea beneficioso para la gran mayoría de la gente.

JMV: Una de las cosas que resultan más originales en este proyecto, especialmente si consideramos las fechas, es el enfoque predominantemente geográfico en lugar de convencionalmente arqueológico.

AG: Eso es una cuestión práctica. Yo tenía que desarrollar un programa de campo que fuera factible con mis medios. Habría dos maneras de hacerlo. Una sería hacer excavaciones de cierta envergadura para sacar muestras directas de sistemas de producción (semillas, huesos, etc) de una serie de yacimientos, contrastando unos en las zonas áridas del Sureste con otros de la Alta Andalucía y emprender una especie de proyecto a gran escala y con grandes recursos estilo European Research Council (ERC) Starting Grant, ipero 
eso no existía por entonces! Yo tenía que ver cómo, consiguiendo 5.000 \$ por aquí, eventualmente 40.000 \$ por allá, podía hacer algo. La primera estrategia era sencillamente imposible, dada mi financiación y mi situación académica. CSUN es una universidad sin programas de doctorado, con lo que era difícil crear un equipo lo suficientemente grande para abordar un programa de estas características. Por eso el site catchment me pareció una estrategia que permitía tener una visión de conjunto, considerar todos los yacimientos ya conocidos de los que uno podía decir que eran poblados y que estaban en diferentes posiciones y áreas, y hacer un estudio sistemático que aportase una visión original. Además, eso era algo que podía hacer solo, si fuera necesario: salir al campo, ir a los yacimientos, andar en diferentes direcciones desde ellos, tomar mis notas sobre el uso del suelo, analizar las fotografías aéreas, realizar los mapas necesarios, etc. Lo podía hacer. La colaboración de Thornes fue esencial en los aspectos geográficos y geomorfológicos. La otra gran ayuda vino de la hija de Don Emilio Gómez Orbaneja ${ }^{30}$, Josefina Gómez Mendoza ${ }^{31}$, una distinguida profesora de Geografía en la Universidad Autónoma de Madrid y amiga de mi familia. Ella me aconsejó que atendiese a las descripciones del Catastro de la Ensenada, pues reflejaban un paisaje completamente premoderno. Entendió exactamente lo que yo estaba haciendo.

JMV: Todos estos factores contribuyen a hacer algo que resultó perfectamente redondo. Ese enfoque predominantemente práctico - geográfico y el recurso al Catastro de Ensenada -no sé si antes algún arqueólogo en España había pensado que en él encontraría datos para su investigación- tuvieron un gran impacto, por lo menos en mi generación. Resultaba una forma totalmente distinta de hacer Arqueología. No sé si eres consciente de ello. Ciertamente, las ideas de fondo, la crítica al funcionalismo sistémico, se remiten al zeitgeist, pero la forma práctica de hacer Arqueología, desplazando el foco de los artefactos al contexto, abrió perspectivas inéditas.

AG: Al fin y al cabo, había sido alumno de Higgs. Él, sin embargo, simplificaba demasiado. Insistía, por ejemplo, en que la gente hiciera sus transectos en línea recta, en vez de seguir los senderos campesinos ya existentes, y en hacer los cálculos después sobre las curvas de nivel. Cuando fui al campo me di cuenta que uno podía ser mucho más práctico.

\footnotetext{
${ }^{30}$ Universidad Carlos III (Madrid), Instituto Figuerola de Historia y Ciencias Sociales, Diccionario de catedráticos españoles de derecho (1847-1943) http://portal.uc3m.es/portal/page/portal/instituto_figuerola/ programas/phu/diccionariodecatedraticos/lcatedraticos/gorbaneja (consulta 09-04-2020).

${ }_{31}$ Real Academia de la Historia (Madrid) https://www.rah.es/dajosefina-gomez-mendoza/ (consulta 09-04-2020)
}

MIMN: Un aspecto interesante del proyecto "El Uso del Suelo en la Prehistoria del Sureste Español" (ESPSE) son las fuentes de financiación por lo que reflejan de las conexiones personales e institucionales que lo hicieron posible.

AG: Las conexiones personales indudablemente influyeron en que recibiera apoyo, por un lado de la mencionada SEP que llevaba Don Emilio Gómez Orbaneja, un buen amigo de mi abuelo y, por otro, de la Fundación Universitaria Española, por entonces dirigida por Don Pedro Sainz Rodríguez, que había sido Ministro de Educación en Burgos en 1936 y fue quien concedió la excedencia a mi abuelo, lo que permitió su salida de España. Pero como ya dije, también recibí una beca de la NEH, de la Fundación Juan March y de la Tinker Foundation, que patrocina estudios iberoamericanos.

JMV: Publicáis los resultados del proyecto en dos obras (Gilman y Thornes 1985, 1986).

AG: Sí, la segunda es una versión resumida que la Fundación March solicitaba a aquellos proyectos financiados. En ese volumen se publican fundamentalmente las conclusiones, no el desarrollo de los datos.

JMV: Muchos conocimos el proyecto gracias a esa publicación. Supongo que la investigación se desarrolló sin una gran interacción con los arqueólogos locales, aparte del apoyo de los organismos que te financiaron y de Fernández-Miranda.

AG: Por entonces el único equipo que trabajaba en la zona era el de Granada. Yo me había dirigido a ellos, sugiriéndoles que mi proyecto de site catchment era complementario a su programa de excavaciones, pero no les interesó la colaboración y básicamente me remitieron a sus publicaciones.

MIMN: Tu contacto con Manuel Fernández-Miranda, Subdirector General de Arqueología de 1979 a 1982 ¿fue el inicio de la relación que os llevó a trabajar juntos en los proyectos en el Sureste y Albacete?

AG: Yo sabía que Manolo era una persona muy activa y positiva, fundamentalmente por Juan Zozaya, que era un amigo común. En 1979, cuando recibí la financiación completa del proyecto, no era necesario tener un permiso para trabajar en el campo, pues no pretendía excavar. Yo iba a los yacimientos y realizaba mis observaciones para el site catchment, pero no recogía material superficial. A los únicos a los que podía importarles era a los propietarios de las tierras y a nadie le importaba pues no había nadie en esos campos. Pero me pareció prudente notificar mi trabajo de una forma oficial. Había tratado de hacerlo antes, cuando estaba Maluquer de subdirector en la Dirección de excavaciones, pero no me recibió.

Así que en el verano de 1979 fui a ver a Manolo al despacho en el Casón del Buen Retiro. Le expliqué mi proyecto y le solicité algún tipo de permiso que yo

Trab. Prehist., 77, N. ${ }^{\circ}$ 1, enero-junio 2020, pp. 7-29, ISSN: 0082-5638

https://doi.org/10.3989/tp.2020.12244 
pudiera mostrar a los guardias civiles rurales o a los propietarios. Pero Manolo estaba perfectamente informado de mi proyecto, pues había sido asesor de mi solicitud para la Fundación Juan March.

Cuando acabé el proyecto del site catchment y empecé a pensar en el siguiente me pareció que debía tener un colaborador nacional y que Manolo era una persona que me podía ayudar en ese sentido. Además, me había caído bien, con lo que me dirigí directamente a él y le dije "¿qué podemos hacer juntos?".

JMV: ¿Cuáles eran tus planes una vez terminado el proyecto?

AG: Había varias posibilidades. Manolo propuso que participase en las prospecciones sistemáticas que quería efectuar en la cuenca de Vera (Delibes de Castro et al. 1996) y en el verano de 1984 pasé un mes allí para ver lo que se podía hacer. Traté de localizar todos los yacimientos de la cuenca de Vera mencionados por los hermanos Siret. Algunos habían desaparecido por completo y muchos estaban seriamente afectados. Además, era un paisaje tan alterado que no era un proyecto de investigación en el que yo pudiera ser de ayuda. Quizás tendría un interés patrimonial, es decir, realizar trabajos de consolidación y documentación del registro prehistórico. Pero lo que se podía encontrar no era una muestra representativa que permitiese contrastar diferentes periodos de una forma sistemática. Era un tipo de proyecto que no habría recibido financiación de las instituciones norteamericanas (Fig. 3).

Otra posibilidad hubiera sido tratar de encontrar un yacimiento en el Sureste que cubriese un periodo no documentado, fundamentalmente el Neolítico, o sea, una época pre-Millares. El yacimiento de Cuartillas era una posibilidad. La apertura de una cantera en ese

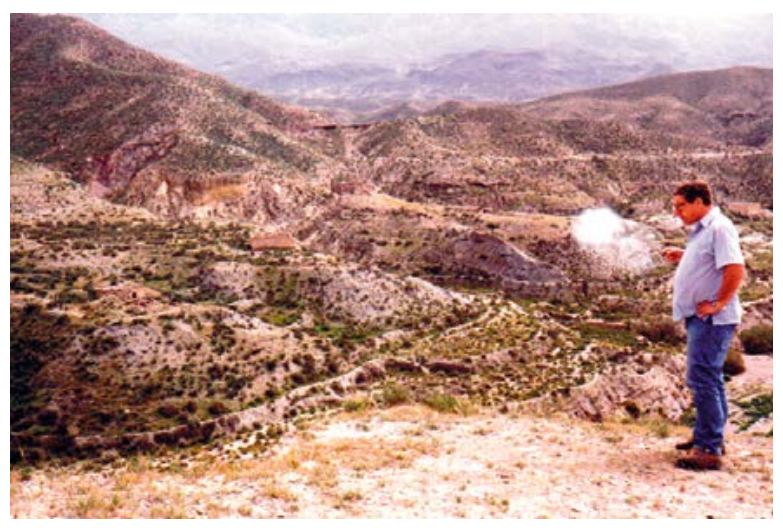

Fig. 3. Antonio Gilman Guillén fumando un puro en el yacimiento de Terrera Ventura (Tabernas, Almería). Fotografía tomada por Kristian Kristiansen durante su visita a los yacimientos del sureste en 1989 (cortesía del autor). cerro permitió que, a finales de junio de 1986, Manolo, María Dolores Fernández-Posse, Concepción Martin y yo hiciéramos una excavación de urgencia, pero no quedaba un relleno significativo. De todas formas, la posibilidad de una estrategia orientada a la excavación de yacimientos no era viable para mí, al carecer de los recursos institucionales necesarios.

Manolo me sugirió entonces visitar las excavaciones de El Acequión y ver el registro de La Mancha. Me propuso realizar un proyecto conjunto y entonces concebí hacer el proyecto del Sureste pero al revés: en lugar de tener los yacimientos conocidos y analizar sus paisajes, tener todo un paisaje y documentar sus yacimientos. A partir de esa idea obtuve algunos fondos para empezar el proyecto de la National Geographic Society (NGS) y luego Manolo sacó bastante dinero de la Junta de Castilla La Mancha y de la Diputación de Albacete para llevarlo a cabo. También recibí ayudas de la Fulbright Foundation y de CSUN.

JMV: Es decir que, de alguna manera, el proyecto de La Mancha es el reverso metodológico del proyecto del Sureste. Se trata de una zona con unas características geográficas muy diferentes, en principio, de las del Sureste.

AG: Es un paisaje menos alterado con un gran número de yacimientos que destacan en el paisaje.

JMV: Me han quedado varias cosas en el tintero respecto al planteamiento del proyecto en La Mancha. A diferencia del tuyo en el Sureste, hecho con un programa bastante concreto y en un número corto de años, en La Mancha se trabaja mucho tiempo.

AG: No tanto. Empecé el trabajo de campo en 1988-1989 y lo concluí con una pequeña campaña en el año 1993. Hice la gran mayoría del trabajo en esos cuatro años. Había desarrollado un proyecto que de alguna forma requería de un sistema de información geográfica antes de que se generalizase su uso en Arqueología ${ }^{32}$. Lo que demoró mucho la publicación fue primero introducir los datos en ArcInfo y luego encontrar alguien que me ayudara a analizarlos. Uno de mis planes de jubilación hubiese sido recibir las clases necesarias para hacerlo yo mismo, pero me encontré con una maravillosa alumna, Chris (Marcella) Brodsky, una especie de genio en esas cosas, que produjo los análisis necesarios y fue co-autora de la publicación final (Fernández-Posse et al. 2008).

JMV: O sea que la impresión que he enunciado antes respecto a la larga duración del proyecto de la Mancha es puramente accidental y se debe a cuestiones prácticas.

\footnotetext{
${ }^{32}$ Por ejemplo, Esri lanzó ArcInfo en 1981.
} 
AG: Hicimos también una pequeña campaña en 2002, pues me había dado cuenta de que los seguimientos arqueológicos realizados en los parques eólicos me permitirían contrastar la calidad de mis resultados. Para ello me dirigí a Mar Zarzalejos, por entonces arqueóloga territorial de Albacete, quien me facilitó la información necesaria. Salimos al campo y pudimos ver exactamente las características de los pocos nuevos yacimientos que se habían encontrado durante las prospecciones y excavaciones de urgencia y así contrastar nuestro método, lo que resultó muy útil.

Pero, aparte de eso, el trabajo de campo estaba sustancialmente cerrado a finales de 1993. Así que el proyecto supuso primero un año completo (1988-1989) más un verano (1990) para localizar los yacimientos, luego dos veranos (1991 y 1992) para describirlos y unas semanas en 1993 para ajustar la descripción de los espacios agrícolas de la zona. Cuando uno tiene 230 yacimientos distribuidos sobre $10.000 \mathrm{~km}^{2}$ las cosas llevan cierto tiempo.

JMV: El planteamiento de este proyecto también difiere de otras formas del tuyo del Sureste. No es una repetición del mismo esquema metodológico. Las magnitudes que estás midiendo en el campo son otras y el escenario es distinto. Por ejemplo, en principio no cabe esperar contrastes entre una extremada aridez y áreas donde el regadío es posible.

AG: La idea es, sencillamente, ver cómo era un paisaje bastante bien conservado de yacimientos de la Edad del Bronce. Estaba claro que muchos yacimientos de La Mancha eran perfectamente reconocibles como tales. Las morras, las motillas y los castillejos (Martínez Navarrete 1988) son yacimientos conspicuos y numerosos. Constituyen un registro que se podía sistematizar. Teníamos noticias de más de la mitad de los yacimientos que documentamos por informaciones previas del Museo de Albacete, así que la cuestión era recurrir a la fotografía aérea para sistematizar la búsqueda.

JMV: ¿Cuál era el propósito general del proyecto? En el caso del Sureste la hipótesis sobre el papel del regadío en la diferenciación social, etc, resultaba evidente, aunque no fuera más que una de las hipótesis que había en juego, pero aquí no resulta tan clara la hipótesis central.

AG: El propósito era ver si existió una jerarquía de yacimientos; por decirlo así, un sistema "feudal" 33 en el que los yacimientos más importantes tienen otros subordinados. El objetivo era contrastar esta hipótesis situando los yacimientos en el paisaje y analizando su distribución. El resultado fue negativo: no encontramos

\footnotetext{
33 Entrecomillado por el entrevistado para denotar la distancia entre el posible modelo de la Edad del Bronce y el feudalismo stricto sensu.
}

que la distribución de los yacimientos grandes con respecto a los recursos fuera muy diferente a la distribución de los yacimientos pequeños. Todos los yacimientos se situaban sobre los espacios más productivos pero, dentro de la escala de yacimientos, los más grandes estaban más separados entre sí que los pequeños, con lo cual no deben constituir un sistema integrado al estilo 'lulliano'34, sino un sistema segmentario.

JMV: Estos resultados también retroalimentan, contrastan o verifican planteamientos que estás haciendo en ese momento a nivel teórico.

AG: Este registro representa lo que ocurre en un paisaje donde es más difícil "enjaular" a los plebeyos, como dice Michael Mann (1986), pues al fin y al cabo llueve lo suficiente como para que en cualquier sitio se pueda obtener una cosecha la mayor parte de los años. Esto no depende de recursos acuáticos limitados, pero hay zonas más y menos productivas y los yacimientos se concentran cerca de las tierras mejores. Es de suponer que, si se hiciesen más excavaciones, uno encontraría bastantes más 'campos de hoyos', pero mi técnica de prospección, basada en la visibilidad topográfica de los yacimientos, no los identificaba.

PDR: Tu reflexión sobre La Mancha parece afectar a la forma en la que concebías la desigualdad social en el Sureste. En tu contribución a From leaders to rulers (Gilman 2002) modificas de alguna manera tu opinión previa (de p. ej. Gilman 1981): afirmas que la existencia de desigualdades sociales sustanciales no resultaba defendible a la vista del registro arqueológico disponible. Este es un giro hacia una interpretación más igualitaria de las sociedades de la Edad del Bronce. ¿Hasta qué punto viene informado por tu conocimiento del registro de La Mancha?

AG: Mi interpretación es el resultado del desarrollo del registro disponible. Una vez que se empiezan a acumular datos procedentes de excavaciones modernas, como las de los alemanes en Fuente Álamo (Schubart et al. 2000), las del equipo de Contreras (2000) en Peñalosa, del equipo de Vicente Lull en Gatas (Chapman et al. 1987) o los muchos otros proyectos inéditos pero sobre los que por entonces teníamos noticias, parecía claro que el registro sugería un sistema que estaba varios peldaños por debajo de un sistema altamente estratificado. Yo había supuesto que podría haber existido una sociedad tributaria a pequeña escala, pero el registro acumulado en las últimas décadas no parecía refrendar esta propuesta con datos. La diferenciación no solo debía observarse en el registro funerario, sino también en el registro doméstico

\footnotetext{
34 Referencia a las tesis sobre la organización del estado argárico de Vicente Lull Santiago y su equipo de la Universitat Autònoma de Barcelona.
} 
y ahora empezábamos a tener una visión más completa a partir de datos empíricos.

¡Qué decir! No es que uno cambie de opinión sobre cómo funciona el mundo. La cuestión es: qué ocurre aquí de una manera concreta. Está claro que mi visión anterior de una estratificación incipiente tenía alguna base, pero la escala era muy pequeña y no estaba claro hasta qué punto estas diferencias fueron hereditarias. Es decir, no fue solo el trabajo en La Mancha, una zona en la que yo siempre supuse que las cosas serían más igualitarias porque mi teoría lo exigía.

El hecho es que el registro de las últimas décadas ha sido producido por arqueólogos que, de alguna forma, han contrastado las distintas propuestas formuladas por Gilman (Gilman y Thornes 1985), Lull (1983), Chapman (1990), etc. Eso ha alimentado una arqueología que se dirige a estudiar aspectos que son muy relevantes. Casos como los de Peñalosa me parecían evidentes: todas las casas son un poco lo mismo, aunque todas las tumbas no lo sean por completo (Contreras y Cámara 2001).

En La Mancha desarrollé un proyecto en un entorno diferente del Sureste en el que, según mi interpretación, no debería observarse una jerarquización pero donde yacimientos importantes, como la motilla del Azuer, bien podrían ser "castillos de señores" (Nájera et al. 1981). El proyecto atendía a la distribución de los yacimientos y recursos en el paisaje para contrastar estas propuestas. Es decir, en este sentido mi trabajo en La Mancha sucede en paralelo y es en sí parte del contexto en el que se produce mi interpretación.

JMV: Bueno, con este comentario podemos cerrar esta primera parte de la entrevista. En la segunda trataremos de abordar algunos de los planteamientos teóricos de tu trabajo y otros aspectos relevantes de tu carrera investigadora.

\section{AGRADECIMIENTOS}

Beatriz Pablos Ochoa, Responsable de Prensa de la Residencia de Estudiantes, posibilitó que los autores se reunieran durante los tres días de entrevista en las mejores condiciones para la grabación. La familia Gilman autorizó la publicación de las fotografías. La Biblioteca Tomás Navarro Tomás (CCHS-CSIC) incorporó de manera inmediata los documentos de grabación y transcripción de la entrevista al Archivo.

\section{ANEXO: ARCHIVO COMPLEMENTARIO}

En la versión en línea (menú Herramientas del artículo) pueden consultarse un archivo complementario en formato word:

AC1: Curriculum vitae completo de Antonio Gilman Guillén.

\section{BIBLIOGRAFÍA}

Adams, R. McC. 1966: The evolution of urban society. Aldine. Chicago. Anes, G. y Gómez Mendoza, A. 2009: Cultura sin libertad. La Sociedad de Estudios y Publicaciones (1947-1980). Ed. Pre-Textos. Valencia.

Annals of Human Biology 1974: "Albert Damon (1918-1973)". Annals of Human Biology 1 (1): 115-119. https://doi.org/10.1080/ 03014467400000131 (consulta 09-04-2020).

Bradley, R. 1993: "An interview with Colin Renfrew". Current Anthropology 34 (1): 71-82. https://doi.org/10.1086/204140

Bricker, H. 2007: Hallam Leonard Movius, Jr. November 28, 1907-May 30, 1987. A biographical memoir. Biographical Memoirs 89, National Academy of Sciences. Washington DC: 243-260.

http://www.nasonline.org/publications/biographical-memoirs/ memoir-pdfs/movius-hallam-1-jr.pdf

Carew, M. 2018: The quest for the Irish Celt: The Harvard Archaeological Mission to Ireland. Irish Academic Press. Newbridge, Irlanda.

Carriazo y Arroquia, J. de M. 1947: "La Edad del Bronce". En R. Menéndez Pidal (ed.): Historia de España. España Primitiva I, Espasa Calpe. Madrid: 755-852.

Caso, A. y Bernal, I. 1952: Urnas de Oaxaca. Memorias del Instituto Nacional de Antropología e Historia II. México.

Chapman, R. W. 1990: Emerging complexity: The Later Prehistory of South-East Spain, Iberia and the West Mediterranean. New Studies in Archaeology, Cambridge University Press. Cambridge.

Chapman, R. W.; Lull, V.; Picazo, M. y Sanahuja, M. E. 1987: Proyecto Gatas: Sociedad y economía en el sudeste de España. C. 2500-900 cal. ANE. 1 La prospección arqueoecológica. British Archaeological Reports, International Series 348, BAR publishing. Oxford.

Childe, V. G. 1953: Man makes himself. Mentor books. The New American Library. Nueva York.

Childe, V. G. 1964: What happened in History. Penguin Books. Baltimore. 1. ${ }^{a}$ ed. 1941.

Chippindale, C. 1994: "Editorial”. Antiquity 68 (261): 687-694.

Christian Jr., W. A. 2020: "Las cenas atlánticas de 29 Lancaster street, Cambridge Massachusetts, 1981-1988". XXIII Coloquio de Historia Canario-Americana (2018), XXIII-071: 1-4.

http://coloquioscanariasamerica.casadecolon.com/index.php/CHCA/ article/view/10468

Clark, J. G. D. 1939: Archaeology and Society. Methuen. Londres.

Clark, J. G. D. 1952: Prehistoric Europe: the economic basis. Methuen. Londres.

Clark, J. G. D. 1954: Excavations at Star Carr: an Early Mesolithic site at Seamer Near Scarborough, Yorkshire. Cambridge University Press. Londres.

Clarke, D. L. 1962: "Matrix Analysis and Archaeology with particular reference to British Beaker Pottery". Proceedings of the Prehistoric Society 28: 371-382. https://doi.org/10.1017/S0079497X00015772

Contreras Cortés, F. (ed.) 2000: Proyecto Peñalosa. Análisis histórico de las comunidades de la Edad del Bronce del piedemonte meridional de Sierra Morena y depresión Linares-Bailén. Arqueología Monografías 10, Junta de Andalucía. Granada.

Contreras Cortés, F. y Cámara Serrano, J. A. 2001: "Arqueología interna de los asentamientos. El caso de Peñalosa”. En M. Ruiz-Gálvez Priego (ed.): La Edad del Bronce ¿Primera Edad de Oro de España? Sociedad, economía e ideología. Crítica. Barcelona: 217-256.

Cowgill, G. L. 1993: "Distinguished Lecture in Archaeology: beyond criticizing New Archaeology". American Anthropologist 95 (3): 551573.

Delibes de Castro, G.; Díaz-Andreu, M.; Fernández-Posse, M. ${ }^{a}$ D.; Martin, C.; Montero, I.; Muñoz, K. y Ruiz, A. 1996: "Poblamiento y desarrollo cultural en la cuenca de Vera durante la prehistoria reciente". En M. ${ }^{a}$ A. Querol y T. Chapa (eds.): Homenaje al profesor Manuel Fernández-Miranda. Complutum Extra 6-1, Servicio de Publicaciones de la Universidad Complutense de Madrid. Madrid: 153-170.

Díaz Cruz, R. (ed.) 2006: Renato Rosaldo: Ensayos en antropología crítica. Col. Estudios Transnacionales, Casa Juan Pablos/Fundación Rockefeller/Universidad Autónoma Metropolitana-Iztapalapa. México. 
Driesch, A. von den 1972: Osteoarchäologische Untersuchungen auf der Iberischen Halbinsel. Stüdien über frühe Tierknochenfunde von der Iberischen Halbinsel 3. München.

Earle, T. K. 1978: Economic and social organization of a complex chiefdom. University of Michigan Anthropological Papers 63, University of Michigan. Ann Arbor.

Evans, Ch. 2011: "Dr John Amyas Alexander: 27/01/1922 - 17/08/2010". Proceedings of the Cambridge Antiquarian Society 100: 209-213. https://archaeologydataservice.ac.uk/archiveDS/ archiveDownload?t=arch-1895-1/dissemination/pdf/PCAS/2011_C/ PCAS_C_2011_209-213_Evans.pdf

Fernández-Posse, M. ${ }^{\mathrm{a}}$ D.; Gilman, A.; Martín; C. y Brodsky, M. 2008: Comunidades Agrarias de la Edad del Bronce en la Mancha Oriental (Albacete). Bibliotheca Praehistorica Hispana 25, Consejo Superior de Investigaciones Científicas. Madrid.

Garrido Domínguez, A. 2015: Augusto y Juan Centeno, dos rondeños en la Residencia de Estudiantes y en la América del exilio hispano. La Serranía. Alcalá del Valle, Cádiz.

Gilman, A. 1974: "Neolithic of northwest Africa". Antiquity 48 (192): 273-282.

Gilman, A. 1975: A Later Prehistory of Tangier Morocco. Bulletin of the American School of Prehistoric Research 29, Peabody Museum. Cambridge.

Gilman, A. 1976: "La secuencia post-paleolítica en el norte de Marruecos". Trabajos de Prehistoria 33: 165-207.

Gilman, A. 1992: "The Iberian Peninsula: 6000 to 1500 B.C.”. En R. W. Ehrich (ed.): Chronologies in Old World Archaeology 1: 295-301 y 2: 238-256. University of Chicago Press. Chicago.

Gilman, A. 1996: "Craft specialization in late prehistoric Mediterranean Europe”. En B. Wailes (ed.): Craft specialization and social evolution: in Memory of $V$. Gordon Childe. University Museum Monograph 93. Philadelphia: 67-71.

Gilman, A. 2002: "Assessing political development in Copper and Bronze Age Southeast Spain". En J. Haas (ed.): From Leaders to Rulers. Kluwer Academic/Plenum Publishers. New York 2002: 59-81. https://doi.org/10.1007/978-1-4615-1297-4 4

Gilman, A. 2018: "Editorial: 25 años de evaluación por pares en Trabajos de Prehistoria". Trabajos de Prehistoria 75 (1): 7-8. https://doi.org/10.3989/tp.2018.12201

Gilman, A. y Thornes, J. B. 1985: Land use and Prehistory in South-East Spain. George Allen \& Unwin. London.

Gilman, A. y Thornes, J. B. 1986: El uso del suelo en la Prehistoria del Sureste español. Serie Universitaria 227, Fundación Juan March. Madrid.

Glick, Th. F. 1970: Irrigation and society in mediaeval Valencia. Harvard University Press. Cambridge.

Guilaine, J. 2011: Archéologie, science humaine. Entretiens avec Anne Lehoërff, Actes sud, Errance. Arles-París.

Harding, A. 2009: "A conversation with Colin Renfrew (Professor Lord Renfrew of Kaimsthorn)". European Journal of Archaeology 11 (23): 143-170. https://doi.org/10.1177/1461957109106371

Hernández, M. 2004: "Necrológica. Irene Mochi-Sismondi, viuda de Jorge Guillén”. El País 1 octubre. https://elpais.com/diario/2004/10/01/ agenda/1096581607_850215.html

Higgs, E. S. y Vita-Finzi, C. 1972: "Prehistoric economies: a territorial approach". En E. S. Higgs (ed.): Papers in Economic Prehistory. Cambridge University Press. Cambridge: 27-36.

Howe, B. 1967: The palaeolithic of Tangier, Morroco: Excavations at Cape Ashakar, 1939-1947. American School of Prehistoric Research bulletin 22. Peabody Museum, Harvard University, Cambridge

Jarman, M. R.; Bailey, G. N. y Jarman, H. N. (eds.) 1982: Early european agriculture. Its foundations and development. Cambridge University Press. Cambridge.

Lacour, P-Y. y Lamy, J. 2018: “Je me sens mieux (un peu) à la marge... Entretien avec Marie-Noëlle Bourguet”. Zilsel 2 (4): 205-228. https://doi.org/10.3917/zil.004.0205

Lewis, O. 1959: Five families: Mexican case studies in the culture of poverty. Basic Books. New York.

Lull, V. 1983: La cultura de El Argar. Un modelo para el estudio de las formaciones económico-sociales prehistóricas. Akal. Madrid.
Mann, M. 1986: The sources of social power. I. A history of power from the beginning to A.D. 1760. Cambridge University Press. Cambridge.

Martínez Navarrete, M. a I. 1988: "Morras, motillas y castillejos. ¿Unidad o pluralidad cultural, durante la Edad del Bronce en La Mancha? En Homenaje a Samuel de los Santos. Instituto de Estudios Albacetenses "Don Juan Manuel". Albacete: 81-92.

Mathewson, K. 2017: "Obituary: Karl Wilhelm Butzer, 1934-2016". Journal of Historical Geography 55. https://doi:10.1016/j.jhg.2016. 12.001

McClelland, D. C. 1961: The Achieving Society. Free Press. New York.

Millán, M. C. 1986: "Stephen Gilman, hispanista”. El País 02/12/1986 https://elpais.com/diario/1986/12/02/agenda/533862001_850215. html

Movius, H. L. 1975: Excavation of the Abri Pataud Les Eyzies (Dordogne). Peabody Museum, Harvard University Bulletin 30. Cambridge.

Nájera, T.; Molina, F.; Aguayo, P. y Martínez, G. 1981: “La Motilla del Azuer (Daimiel, Ciudad Real). Campaña de 1981". Cuadernos de Prehistoria de la Universidad de Granada 6: 293-306.

Nuñez-Johnsson, K. 2015: Gertrude Duby Blom (1901-1993). Combatiente de la Resistencia. Col. Les Suisses dans le monde, Infolio ed. Crausaz, Suiza.

Nuzzo, R. 2006: "Profile of Michael E. Moseley". Proceedings of the National Academy of Sciences of teh United States of America 103 (13): 4.805-4.807. https://doi.org/10.1073/pnas.0600844103

Olivé Negrete, J. C. 1988: "Presencia de Vere Gordon Childe en la arqueología Mexicana”. En L. Manzanilla (ed.): Coloquio V. Gordon Childe. Estudios sobre la revolución neolítica y la revolución urbana (México 1986): 15-23. México.

Outram, A. K. y Bogaard, A. 2019: Subsistence and society in Prehistory: new directions in Economic Archaeology. Cambridge University Press. Cambridge.

Paardekooper, R. 2009: "Interview with John Coles. Reflecting on experimental archaeology". euroREA 6: 65-68. https:/exarc.net/sites/ default/files/exarc-eurorea_6_2009-john_coles_reflecting_on_ experimental archaeology.pdf

Potts, D. T. 2012: "Technological transfer and innovation in Ancient Eurasia". En J. Renn (eds.): The globalization of knowledge in History. Max Planck Research Library for the History and Development of Knowledge Studies 1. Berlín: 105-123.

Redfield, R. 1930: Tepoztlan: a mexican village. A study of folk life. The University of Chicago Press. Chicago.

Renfrew, C. 1967: "Colonialism and megalithismus". Antiquity 41 (164): 276-288.

Renfrew, C. 1970: "The Autonomy of the South-East European Copper Age". Procedings of the Prehistoric Society 35: 12-47. https://doi.org/10.1017/S0079497X00013396

Renfrew, C. 1972: The emergence of civilization: the Cyclades and the Aegean in the third millennium B.C. Methuen. London.

Renfrew, C. 1987: "An interview with Lewis Binford". Current Anthropology 28 (5): 683-694. https://doi.org/10.1086/203611

Renfrew, C. 2004: "Daniel, Glyn Edmund (1914-1986)" [rev.]. Oxford Dictionary of National Biography, Oxford University Press. Oxford.

Risch, R. 2013: "Una entrevista con Hermanfrid Schubart, Moraira (Alicante, 14-XI-2012)". Trabajos de Prehistoria 70 (2): 231-240. https://doi.org/10.3989/tp.2013.12110

Robin, C. 2014: "Elizabeth Brumfiel, 1945-2012". Ancient Mesoamerica 25 (1): 1-4.

Rocquet, Cl-H. 1982: Les Racines du monde. Entretiens avec André Leroi-Gourhan. Belfond. París.

Rodríguez Yunta, L.; Vidal Liy, J. I. y Martínez Navarrete, M. ${ }^{\text {a }}$. 2019: "Análisis bibliométrico de la revista Trabajos de Prehistoria en el contexto de las revistas españolas de Arqueología y Prehistoria recogidas por Scopus e ÍnDICEs CSIC". Trabajos de Prehistoria 72 (2): 199-218. https://doi.org/10.3989/tp.2019.12233

Rose, C. H. 1988: “In memoriam. Stephen Gilman (1917-1986)”. Cervantes: Bulletin of the Cervantes Society of America 8 (2): 251-253.

Rubio Tovar, J. 1997: "Cincuenta años de Literatura europea y Edad Media Latina de E. R. Curtis (1948-1998)". Revista de Occidente 197: 154-166. 
Ruiz-Zapatero, G. y Vicent, J. M. 1992: “"Todo arqueólogo tiene algo de teórico...' Una entrevista con Leo S. Klejn”. Trabajos de Prehistoria 49: 11-25. http://tp.revistas.csic.es/index.php/tp/article/ view/504/521

Sabloff, J. A. 1974: "Ode to Margaret on her retirement". Harvard University news about the Peabody Museum and Department of Anthropology, Fall: 1 y 8 .

Sabloff, J. A. 2004: "Gordon Randolph Willey. 7 March 1913-28 April 2002". Proceedings of the American Philosophical Society 148 (3): 405-410.

Sahlins, M. D. 1958: Social stratification in Polynesia. The University of Washington Press. Seattle.

Salinas, P. 1925: Poema de Mio Cid, "en romance vulgar y lenguaje moderno". Serie Musas lejanas 8, Revista de Occidente. Madrid, 1. a ed.

Schubart, H.; Arteaga, O. y Pingel, V. 2000: Fuente Álamo: las excavaciones arqueológicas 1977-1991 en el poblado de la Edad del Bronce. Arqueología Monografías 8, Consejería de Cultura. Sevilla.

Thornes, J. B. 1976: Semi-arid erosional systems: case studies from Spain. Geographical Papers 7, London School of Economics. Londres.

Treaster, J. B. 1981: "Hugh Hencken; Noted Archeologist and Museum Chief". The New York Times, September 4. 12, Section A. https:// www.nytimes.com/1981/09/04/obituaries/hugh-hencken-79-notedarcheologist-and-museum-chief.html

Triana Cardona, W. 2018: "Jorge Guillén y Américo Castro: amistad en la diáspora”. ABC Castilla y León 03/10/2018.

Vogt, E. Z. 1994: Fieldwork among the Maya: Reflections on the Harvard Chiapas Project. University of New Mexico Press. Albuquerque.

Wailes, B. 1996: "Craft specialization in late prehistoric Mediterranean Europe". En B. Wailes (ed.): Craft specialization and social evolution: in Memory of $V$. Gordon Childe. University Museum Monograph 93. Philadelphia: 67-71.

Wittfogel, K. A. 1957: Oriental despotism. Yale University Press. New Haven.

Wolf, E. R. 1959: Sons of the shaking earth: the people of Mexico and Guatemala-Their land, history, and culture. University of Chicago Press. Chicago.

Wright, H. G. (ed.) 1928: "Prominent DELTASIG's: Stephen W. Gilman, Psi”. The DELTASIG XX (3): 195-197. https://www.deltasigmapi. org/docs/default-source/DELTASIG-Magazine/1920s/1928-deltasigvol-20-no-3-may.pdf?sfvrsn=3aad699b_2

Yofee, N. 1997: "Robert McCormick Adams: an archaeological biography”. American Antiquity 62 (3): 399-413. 